\title{
Simvastatin Evokes An Unpredicted Antagonism For Tamoxifen In MCF-7 Breast Cancer Cells
}

This article was published in the following Dove Press journal:

Cancer Management and Research

\author{
Amel B Ibrahim' \\ Hala F Zaki ${ }^{2}$ \\ Walaa Wadie ${ }^{2}$ \\ Mervat M Omran (1D) \\ Samia A Shouman $\mathbb{D D}^{3}$ \\ 'Department of Pharmacology, Faculty of \\ Medicine, Zawia University, Zawiya, Libya; \\ ${ }^{2}$ Department of Pharmacology and \\ Toxicology, Faculty of Pharmacy, Cairo \\ University, Cairo, Egypt; ${ }^{3}$ Department of \\ Cancer Biology, Pharmacology Unit, \\ National Cancer Institute, Cairo \\ University, Cairo II796, Egypt
}

\begin{abstract}
Purpose: Tamoxifen (TAM) is a non-steroidal antiestrogen drug, used in the prevention and treatment of all stages of hormone-responsive breast cancer. Simvastatin (SIM) is a lipidlowering agent and has been shown to inhibit cancer cell growth. The study aimed to investigate the effect of the combination of TAM and SIM in the treatment of estrogen receptor positive $(\mathrm{ER}+)$ breast cancer cell line, MCF-7, and in mice-bearing Ehrlich solid tumors.
\end{abstract}

Methods: MCF-7 cells were treated with different concentrations of TAM or/and SIM for 72 hours and the effects of the combination treatment on cytotoxicity, oxidative stress markers, apoptosis, angiogenesis, and metastasis were investigated using different techniques. In addition, tumor volume, oxidative markers, and inflammatory markers of the combined therapy were explored in mice bearing solid EAC tumors.

Results: The results showed that treatment of MCF-7 cells with the combination of $10 \mu \mathrm{M}$ TAM, and $2 \mu \mathrm{M}$ SIM significantly inhibited the increase in oxidative stress markers, LDH, and NF-kB induced by TAM. In addition, there was a significant decrease in the total apoptotic ratio, caspase- 3 activity, and glucose uptake, while there was a non-significant change in Bax/bcl-2 ratio compared to the TAM-treated group. Using the isobologram equation, the drug interaction was antagonistic with combination index, $\mathrm{CI}=1.18$. On the other hand, the combination regimen decreased VEGF, and matrix metalloproteinases, MMP $2 \& 9$ compared to TAM-treated cells. Additionally, in vivo, the combination regimen resulted in a non-significant decrease in the tumor volume, decreased oxidative markers, and the protein expression of TNF- $\alpha$, and NF- $\kappa \mathrm{B}$ compared to the TAM treated group.

Conclusion: Although the combination regimen of TAM and SIM showed an antagonistic drug interaction in MCF-7 breast cancer, it displayed favorable antiangiogenic, antimetastatic, and anti-inflammatory effects.

Keywords: combined therapy, antitumor effect, apoptosis, oxidative markers, VEGF

\section{Introduction}

Breast cancer is the most common female cancer worldwide. ${ }^{1}$ Estrogen receptor positive $(\mathrm{ER}+)$ breast cancer represents more than $70 \%$ of all breast cancer patients. ${ }^{2}$ Tamoxifen (TAM) is the mainstay in the treatment and prevention of ER+ breast cancer in both pre- and postmenopausal females. It reduces breast cancer recurrence by $50 \%$ and the annual mortality rate by $31 \%$. TAM exerts its antiproliferative effect via binding competitively to estrogen receptor, thereby blocking the mitogenic effect of estrogen. ${ }^{3}$ In addition, it induces apoptosis of cancer cells through several distinct mechanisms including the modulation of signaling proteins, such as protein kinase $C$, transforming growth factor- $\beta$ (TGF- $\beta$ ), and the upregulation of $\mathrm{p} 53 .{ }^{4,5}$ Despite this
Correspondence: Samia A Shouman Department of Cancer Biology, National Cancer Institute, Cairo University, Kasr Al Eini Street, Fom El Khalig, Cairo I I796, Egypt

Fax $+202-23644720$

Email samia.shouman@nci.cu.edu.eg 
success, $20-30 \%$ of tumors develop resistance to tamoxifen therapy after 3-5 years of its intake, in addition to its sideeffects. $^{6}$

Obesity is a risk factor for $(\mathrm{ER}+)$ postmenopausal breast cancer patients, attributed to increases in circulating insulin, insulin-like growth factors, estrogen, and inflammatory cytokines. $^{7,8}$ Hypercholesterolemia, a comorbidity of obesity, has been identified as an independent risk factor for breast cancer. ${ }^{9,10}$ Statins, the 3-hydroxy-3-methylglutaryl HMG CoA reductase (HMGCR) inhibitors, are among the commonly approved drugs to decrease cholesterol levels and prevent cardiovascular diseases. Beyond their cardiovascular effects, statins have been reported to have possible benefits as immunomodulators in organ transplantation, induction of bone marrow stimulation, and inhibition of cancer progression. ${ }^{11-13}$ In addition, a potential role for simvastatin as a radiosensitizer for aggressive breast cancer has been suggested. ${ }^{14}$ This sensitizes the radioresistant esophageal cancer cells and reversing epithelial-mesenchymal transition (EMT) process via the PTEN-PI3K/AKT pathway. ${ }^{15}$ Moreover, SIM was able to inhibit DNA replication licensing factor (MCM7), and dysfunction of tumor suppressor retinoblastoma $(\mathrm{Rb})$ is a common feature in various tumors that contributes to cancer cell stemness and drug resistance to cancer therapy. It reduced the $\mathrm{Rb}$ signals and influenced the expression of cyclinD1 and p27 in tamoxifen resistant cells. ${ }^{16}$ Despite the convincing preclinical evidence for the anticancer effects of statins, their role in breast cancer recurrence and mortality is still not conclusive. Some data support a beneficial role for their uses in breast cancer management, other studies are less promising and argue against their prescription in cancer treatment. $^{17-19}$ Moreover, all these studies were carried out using statins alone, its effectiveness in combination with TAM as neoadjuvant therapy in ER+ breast cancer has not yet been explored. Therefore, it is worthwhile examining whether SIM can potentiate the tumor response of TAM, the conventional breast cancer therapy or not. The importance of this interaction is intensified as TAM is a pioneering medicine for the treatment and prevention of breast cancer and confers dramatic reductions in breast cancer recurrence and mortality. In addition, SIM may be prescribed with TAM for breast cancer patients because of hypercholesterolemia. Therefore, the current study was designed to investigate the combined antitumor effect of TAM and SIM in the ER+ breast cancer cell line, MCF-7, as well as in mice bearing Ehrlich solid tumor as a model of mammary carcinoma established in studying the effect of chemotherapy in vivo.

\section{Materials And Methods \\ Drugs}

Tamoxifen (TAM citrate) and Simvastatin (SIM) were obtained from Sigma Aldrich Chemical Co. (St. Louis, $\mathrm{MO})$. They were dissolved in dimethyl sulfoxide (DMSO) to yield stock solution $1 \mathrm{mM}$ and serially diluted in RPMI-1640 supplemented medium immediately before use to yield a concentration range of $10-60 \mu \mathrm{M}$ for the MCF-7 cell line. The final concentration of DMSO never exceeded $0.1 \%(\mathrm{v} / \mathrm{v})$ in both control and treated samples.

Simvastatin (SIM) was obtained from Sigma Aldrich Chemical Co. (St. Louis, MO). This is obtained as white powder soluble in DMSO to yield $1 \mathrm{mM}$ then serially diluted in RPMI-1640 supplemented medium immediately before use to yield a concentration range of $0.5-2.5 \mu \mathrm{M}$ for MCF-7 cell line.

\section{Chemicals}

Dimethyl sulfoxide (DMSO), RPMI-1640 Medium, fetal bovine serum (FBS), Penicillin/Streptomycin antibiotic, trypsin-EDTA, Ellman's reagent [5,5-Dithio-bis-(2-nitrobenzoic acid)], reduced glutathione,1,1.3,3-tetramethoxypropane, trichloroacetic acid (TCA), thiobarbituric acid, $\beta$-mercaptoethanol, sodium dodecyl sulfate (SDS), sodium bicarbonate, methanol, and sulforhodamine B were all purchased from Sigma-Aldrich Chemical Co. (St. Louis, $\mathrm{MO}$ ). Acetonitrile was obtained from Alliance Bio Co., USA. All other chemicals and solvents used were of the highest purity grade available.

\section{Human Cancer Cell Line}

Human breast carcinoma cell line MCF-7 was obtained from American Type Culture Collection (ATCC; Washington DC) and stored frozen in liquid nitrogen $\left(-180^{\circ} \mathrm{C}\right)$. The tumor cell line was maintained as monolayer cultures in RPMI-1640 supplemented with $10 \%$ FBS and 1\% penicillin- Streptomycin.

\section{Animals}

Female Swiss albino mice weighing 20-25 were obtained from the animal facility of the National Cancer Institute (NCI), Cairo University, Egypt. Animals were kept under standard conditions and were allowed free access to a standard requirement diet and water ad libitum. All the procedures relating to animal care and treatments are 
strictly adhered to the Guide for the Care and Use of Laboratory Animals published by the US National Institute of Health (Publication No.85-23, revised 1996). The protocol was approved by the research ethics committee of Animal Care, Faculty of Pharmacy, Cairo University, Egypt (Permit Number: PT 1567).

\section{In-Vitro Parameters Cytotoxicity Assay}

Cytotoxicity was determined using the sulforhodamine $\mathrm{B}$ dye (SRB) method according to Skehan et al. ${ }^{20}$ Briefly cells were seeded in 96-well microtiter plates at a concentration of $3 \times 10^{3}$ cells/well. They were left to attach for 24 hours before incubation with drugs. The cells were treated with different concentrations of TAM (10-60 $\mu \mathrm{M})$, and $\operatorname{SIM}(0.5-16 \mu \mathrm{M})$ for 72 hours. For designing an effective combination regimen for both drugs, we used half the $\mathrm{IC}_{50}$ of TAM $(10 \mu \mathrm{M})$ with different concentrations of SIM less than $\operatorname{IC}_{50}(0.5,1,1.5,2$, $2.5 \mu \mathrm{M})$ to choose the best inhibited concentration. The optical density (OD) of each well was measured spectrophotometrically at $570 \mathrm{~nm}$ using an ELISA microplate reader (TECAN Sunrise ${ }^{\mathrm{TM}}$, Germany). The mean values were estimated as a percentage of cell viability as follows: $(\mathrm{OD}$ of treated cells/OD of control cells $) \times 100$. The $\mathrm{IC}_{50}$ value (the concentration that produces $50 \%$ inhibition of cell growth) of each drug was calculated using dose response curve-fitting models (Graph-Pad Prism software, version 5).

\section{Evaluation Of Drug Interaction}

To assess the modulatory effect of SIM on the cytotoxicity of TAM, the degree of interaction between the two drugs was calculated using the combination index according to the isobologram equation, according to Chou. ${ }^{21}$ The combination index $(\mathrm{CI})=1 / 1+2 / 2$, where 1 and 2 signify the respective concentrations of TAM and SIM used in combination to produce a fixed level of inhibition, while 1 and 2 represent their concentrations that are alone able to produce the same magnitude of effect. If the CI is $<1$, the effect of combination is synergistic, or if it is equal to 1 or $>1$, the effect is additive or antagonistic.

\section{Determination Of Lipid Peroxidation And Non-Protein Reduced Thiols Content (Glutathione Content)}

Cells were cultured in T75 flasks and treated with TAM, SIM, and their combinations for 72 hours. Lipid peroxidation products were determined by measuring malondialdehyde
(MDA) level in cell lysate using the method of MDA content. $^{22}$

Reduced glutathione (GSH) in the cell lysate was determined according to the method of, it is based on the reduction of Ellman's reagent [5,5'-dithio-bs-(2-nitrobenzoic acid)] by $\mathrm{SH}$ groups to form 1 mole of 2-nitro-5-mercaptobenzoic acid per mole of $\mathrm{SH}^{23}$ The optical density was measured at $412 \mathrm{~nm}$ against a reagent blank and the results were expressed as $\mu \mathrm{mol} / \mathrm{mg}$ protein.

\section{Determination Of Superoxide Dismutase (SOD) Activity And Nitrate/Nitrite (NOx) Content}

Superoxide dismutase (SOD) activity was assayed using a standard commercial SOD Assay kit (Sigma-Aldrich, St. Louis, MO). Enzymatic activity was determined according to the manufacturer's instructions. The OD was read at $340 \mathrm{~nm}$. The results were expressed in the form of $\mathrm{U} / \mathrm{mL}$.

Total nitrate/nitrite (NOx) was measured in the cell culture media as stable end product, nitrite.According to the method of Miranda et $\mathrm{al}^{24}$ the assay is based on the reduction of nitrate by vanadium trichloride combined with detection by the acidic Griess reaction. The diazotization of sulfanilic acid with nitrite at acidic $\mathrm{pH}$ is subsequent coupling with $\mathrm{N}-(10$-naphthyl) ethylenediamine to an intensely colored product that is determined spectrophotometrically at $540 \mathrm{~nm}$ and expressed as $\mathrm{nmol} / \mathrm{mg}$ protein

\section{Determination Of Protein Concentration}

Protein concentration was assessed in the medium and cell lysate by using the Bradford method. ${ }^{25}$ The method is based on the binding of Coomassie brilliant blue G-250 dye with protein and forming a complex which can be detected spectrophotometrically at $595 \mathrm{~nm}$ then the concentration was determined using a standard calibration curve.

\section{Determination Of Glucose Uptake And LDH Level}

Glucose in media before and after treatment was determined using a colorimetric assay kit (Randox, County Antrim, UK) according to the manufacturer's instructions. The OD was read at $340 \mathrm{~nm}$. The results were expressed as $\mathrm{mg} / \mathrm{dL}$.

LDH level was determined in cell culture supernatant using a colorimetric assay kit (Randox) according to the manufacturer's instructions. The OD was read at $500 \mathrm{~nm}$. The results were expressed as U/L.

\section{Determination Of The Enzymatic Activity Of Caspase-3 And VEGF Level}

Caspase-3 activity and VEGF level were measured in cell culture supernatant using an ELISA kit (Sunlong Biotech, 
Hangzhou, China) according to the manufacturer's protocol. The OD of each well was measured at $450 \mathrm{~nm}$ and the results were expressed as $\mathrm{pg} / \mathrm{mL}$.

\section{Determination Of mRNA Expression Of Bax And Bcl-2}

The expression of Bax and bcl-2 in MCF-7 cells was quantified using quantitative real-time PCR. Total RNA was extracted from the control and treated with Trizol Reagent (Invitrogen, Carlsbad, CA), and the quality and the quantity of the RNA was determined using nanodrop (Thermo Fisher, UK). Single-stranded RNA was converted into complementary DNA using cDNA Reverse Transcription Kit (Applied Biosystems, Waltham, MA). Thermal cycling was commenced using thermocycler (Biometra, Germany) according to the following conditions: $25^{\circ} \mathrm{C}$ for 10 minutes, $37^{\circ} \mathrm{C}$ for 120 minutes, $85^{\circ} \mathrm{C}$ for 5 minutes, and $4^{\circ} \mathrm{C}$ for $\infty$. Real-time PCR analysis was conducted using the thermocycler Step One ${ }^{\mathrm{TM}}$ (Applied Biosystems). Each RT-reaction served as a template in a $20 \mu \mathrm{L}$ PCR reaction containing 0.2 $\mu \mathrm{mol} / \mathrm{L}$ of each primer and SYBR green master mix (Thermo Fisher Scientific, UK). Primer-set sequences are described in Table 1. Real-time PCR reactions were performed at $50^{\circ} \mathrm{C}$ for 2 minutes, $95^{\circ} \mathrm{C}$ for 10 minutes, followed by 45 cycles at $95^{\circ} \mathrm{C}$ for 15 minutes and $56^{\circ} \mathrm{C}$ for 1 minute. The mRNA levels of these genes were normalized to GAPDH $(\triangle \mathrm{CT})$. The $\Delta \mathrm{CT}$ was calibrated against an average of the control sample.

\section{Annexin V Assay For The Assessment Of Apoptosis} MCF7 cells were plated $\left(1 \times 10^{6}\right.$ cells/well) in six-well plates, allowed to attach overnight, and treated with TAM or/and SIM for 72 hours of treatment. The adherent and floating cells were collected, washed twice with $\left(4^{\circ} \mathrm{C}\right)$ PBS, and resuspended in $400 \mu \mathrm{L}$ binding buffer. Annexin V-FITC apoptosis detection kit (Beckman Coulter, Brea, CA) was used as the manufacturer's recommendation using a Beckman Coulter Epics XL Flow Cytometer.

\section{Determination of MMP-2 And 9 Activities By Gelatin Zymography}

MCF-7 cells were treated with TAM and/or SIM for 72 hours. Cells were harvested and protein concentrations of each sample was determined by Bradford method. Briefly, MMP-2 and MMP-9 enzymatic activities in collected medium were determined by sodium dodecyl sulfate - polyacrylamide gel electrophoresis (SDS PAGE) gelatin zymography. ${ }^{26}$ Gel was incubated for 15 minutes in the renaturation buffer containing $2.5 \%$ Triton X-100 at room temperature then it was incubated for 1 hour. The gel was washed twice with water, then incubated overnight at $37^{\circ} \mathrm{C}$ in developing buffer (50 mM Tris- $\mathrm{HCl}, \mathrm{pH} 7.5,0.2 \mathrm{M} \mathrm{NaCl}$, Triton-X $5 \mathrm{~mL}$, and $5 \mathrm{mM} \mathrm{CaCl}_{2}$ ) and stained with Coomassie brilliant blue R1 250 for 1 hour and de-stained in a $10 \%$ methanol and $5 \%$ acetic acid solution. Enzyme digested regions were observed as clear bands against a dark blue background. Gel was scanned using an image Scanner III LabScan6.0. To determine the mean intensity of each band (mean pixel), the band densities were measured with Scion Image Beta 4.0.2 (Scion Co., Frederick, MD) software.

\section{Determination Of TAM Uptake Using Liquid Chromatography-Tandem Mass Spectrometry (LC/MS/MS) Analysis}

To test if the addition of SIM affects the intracellular levels of TAM, cells were seeded at a density of $2 \times 10^{4}$ cells/well in 24-well plates and left for 24 hours. Cells were incubated with TAM alone and with SIM, medium was then aspirated at $0,2,4,6,24$, and 48 hours, centrifuged, and the supernatants were used for assay. Two hundred microliters of the supernatant were mixed thoroughly with $200 \mu \mathrm{L}$ acetonitrile (Alliance Bio, USA) and centrifuged at 1,400 rpm for 15 minutes at $4^{\circ} \mathrm{C}$. The clear supernatant was injected into an AB SCIEX LC/MS/MS system (AB SCIEX 3200 QTRAP, Germany) adapting the method for TAM determination. ${ }^{27}$ The system is equipped with an electrospray ionization (ESI) source and an Agilent 1260 affinity HPLC system, consisting of a vacuum degasser, a binary pump, and an autosampler to determine the concentration of TAM. Analyst 1.5.2 software was used for data acquisition and processing. The analytical column used was Agilent Poroshell 120-C18 $(50 \mathrm{~mm} \times 3 \quad \mathrm{~mm} \times 2.7 \mu \mathrm{m}$, Agilent, Germany) at $25^{\circ} \mathrm{C}$. The mobile phase consists of $0.1 \%$ formic $\mathrm{acid} /$ water (solvent $\mathrm{A}$ ) and $0.1 \%$ formic acid/acetonitrile

Table I Oligonucleotides Used In The qPCR Analysis

\begin{tabular}{|l|l|l|l|l|}
\hline & GenBank Accession No. & Forward Primer & Reverse Primer & Product \\
\hline GAPDH & J04038 & GTGGAGTCCACTGGCGTCTT & GCAAATGAGCCCAGCCTTC & I06 \\
BAX & NM_004324.3 & CCTTTTCTACTTTGCCAGCAAAC & GAGGCCGTCCCAACCAC & I22 \\
BCL-2 & NM_000633.2 & ATGTGTGTGGAGAGCGTCAACC & GCATCCCAGCCTCCGTTATC & I36 \\
\hline
\end{tabular}


(solvent B), delivered at a flow rate of $0.5 \mathrm{~mL} / \mathrm{min}$. Mass spectrometric analysis was performed in the positive ion mode.

Immunohistochemical Staining Of NF- $\kappa$ B, Bax, And Bcl-2 For the detection of immunoreactive proteins in breast cancer cells, MCF-7 was treated with $10 \mu \mathrm{M}$ of TAM, 2 $\mu \mathrm{M}$ of SIM, and their combination, in addition to control for 72 hours then cells were fixed with $4 \%$ paraformaldehyde and incubated for 30 minutes at room temperature in blocking solution containing $5 \%$ bovine serum albumin in Tris-buffered saline TBS. The cells were then incubated overnight at $4{ }^{\circ} \mathrm{C}$ with primary antibodies specific to NF- $\mathrm{kB}$, Bax, and bcl-2 (Abcam, Cambridge, UK) at a concentration of $1 \mu \mathrm{g} / \mathrm{mL}$. Thereafter, samples were incubated at room temperature for 1 hour with goat antirabbit secondary antibody, sections were then washed with TBS and incubated in diaminobenzidine (DAB) solution containing $\mathrm{H}_{2} \mathrm{O}_{2}$ and Counter stain was performed using hematoxylin, and the slides were visualized using a digital camera installed on a Leica DMLB2 light microscope (Leica Microsystems, Germany).

\section{In-Vivo Study}

\section{Determination Of Tumor Volume And Tumor Mass}

Ehrlich carcinomas (EAC)-cells $\left(2 \times 10^{6}\right)$ were transplanted subcutaneously in the right thigh of the lower limb mice. Twenty-four mice with a palpable tumor mass $\left(100 \mathrm{~mm}^{3}\right)$ that developed within 7 days after implantation were divided into four groups each containing six animals. Group I mice served as the control group. Group II animals received TAM $(2.5 \mathrm{mg} / \mathrm{kg})$ by oral gavage. ${ }^{28}$ Group III mice were given SIM $(2 \mathrm{mg} / \mathrm{kg})$ by oral gavage. ${ }^{29}$ Group IV mice were treated by the combination of both TAM and SIM at the pre-mentioned doses for a period of 8 days. The change in tumor volume was measured every other day using a Vernier caliper and calculated by the following formula.

$$
\text { Tumor volume }\left(\mathrm{mm}^{3}\right)=4(\mathrm{~A} / 2)^{2} \mathrm{X}(\mathrm{B} / 2) / 3
$$

where $\mathrm{A}$ and $\mathrm{B}$ denote the minor and the major tumor axis, respectively. Mice were sacrificed on day 9, and tumors were dissected and weighed.

\section{Determination Of MDA, GSH, SOD Activity, And NOx Level In Solid Tumor Tissue}

Twenty-four hours after the last treatment, animals were anesthetized by ketamine $(100 \mathrm{mg} / \mathrm{kg}$ ) (Keiran; EIMC Pharmaceuticals Co., Cairo, Egypt), then sacrificed by decapitation and the tumor was excised, weighed, and then homogenized using a Branson sonifier (250, VWR Scientific, Danbury, CT). The homogenates were centrifuged at $800 \mathrm{~g}$ for 5 minutes at $4^{\circ} \mathrm{C}$ to separate the nuclear debris and then the supernatant was centrifuged again at $10,500 \mathrm{~g}$ for 20 minutes at $4^{\circ} \mathrm{C}$. Levels of MDA, GSH, SOD, and NOx were determined as previously described.

\section{Histopathological Study}

The samples were fixed in $10 \%$ neutral buffered formalin, dehydrated through alcohols, cleared in xylene, and then embedded in paraffin wax. Sections (5 mm thick) were stained with haematoxylin and eosin.

Immunohistochemical Detection Of TNF- $\alpha$ And NF- $\kappa B$ Paraffin embedded EAC sections were first rehydrated in xylene and then in graded ethanol solutions. Primary antibodies specific to NF- $\kappa \mathrm{B}$ and TNF- $\alpha$ (Abcam, Cambridge, $\mathrm{UK})$ at a concentration of $1 \mu \mathrm{g} / \mathrm{mL}$ antibodies were used and thereafter processed as detailed above.

\section{Statistical Analysis}

Differences between obtained values $($ mean $\pm S D)$ were carried out by one-way analysis of variance (ANOVA) followed by the Tukey-Kramer multiple comparison test. ANOVA with repeated and mixed model followed by Bonferroni test for adjustment for multiple comparisons was used for comparison between the two groups in TAM uptake. A value of 0.05 or less was taken as a criterion for a statistically significant difference.

\section{Results}

\section{TAM, SIM, And Their Combination Inhibited Cellular Proliferation Of Breast Cancer Cell Lines MCF-7}

Treatment of TAM for 72 hours produced a decrease in cell survival in breast cancer cell lines with IC 50 of $20 \mu \mathrm{M}$ in MCF-7 (Figure 1A). On the other hand, the IC50 values of SIM were $2.05 \mu \mathrm{M}$ in MCF-7 (Figure 1B). Our results showed that the most effective concentration of SIM that impeded the cell viability in the cell lines was $2 \mu \mathrm{M}$. Therefore, the following regimen (10 $\mu \mathrm{M}$ TAM with $2 \mu \mathrm{M}$ SIM) for MCF-7 were used for all the following studies (Figure 1C).

\section{The Combination Regimen Of TAM And SIM Was Antagonistic In MCF-7 Cells}

An evaluation of the drug interaction was carried out using the isobologram analysis. An antagonistic drug interaction 
A

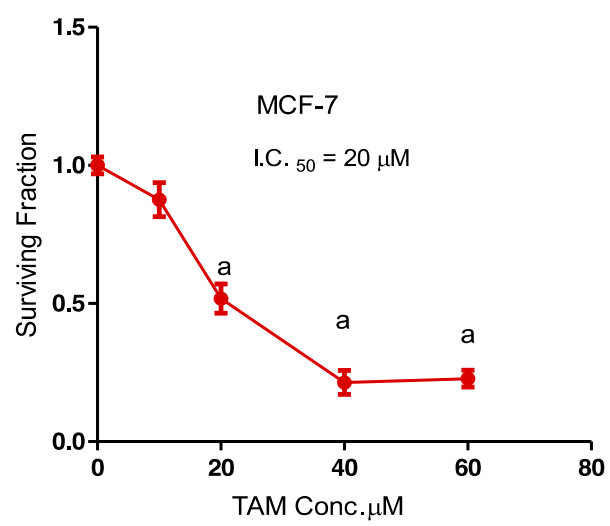

C

MCF-7

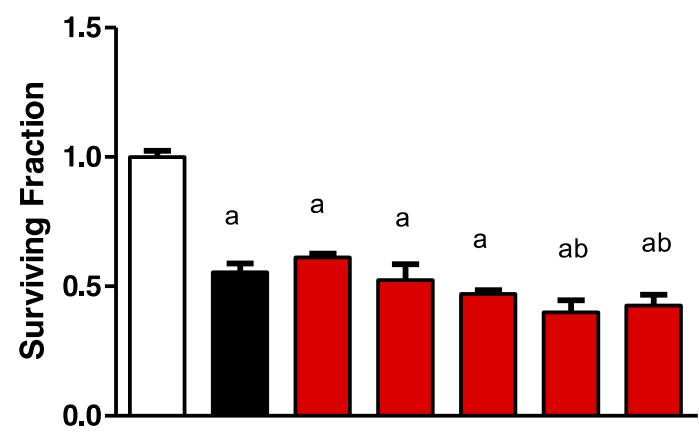

B

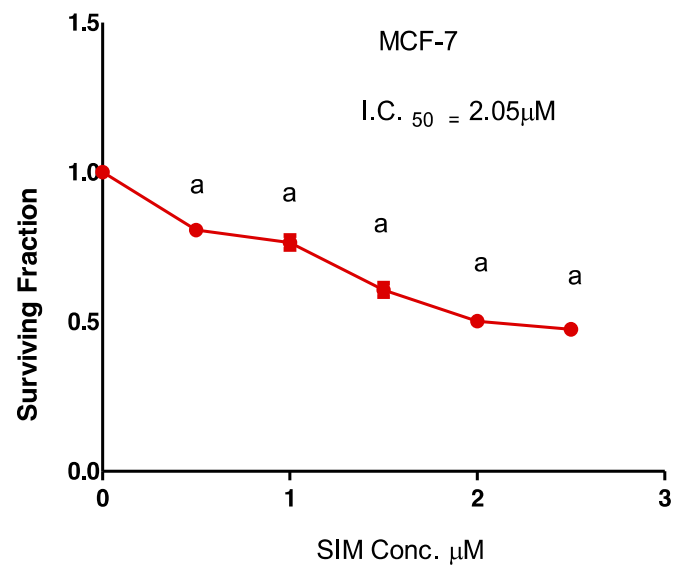

D

MCF-7

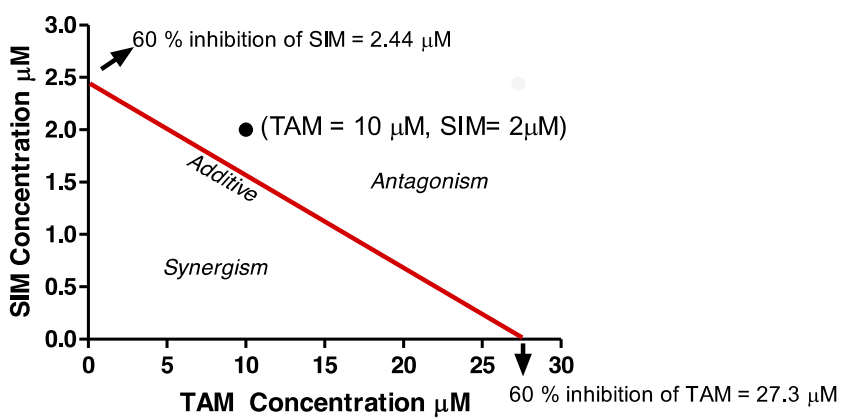

$\mathrm{TAM} \mu \mathrm{M}-10++\quad+\quad+\quad+$

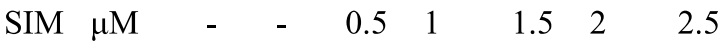

Figure I Cytotoxicity of treatment of TAM, SIM, and their combinations in MCF-7 breast cancer cell line after 72 hours. Surviving fraction of MCF-7 treated with different concentrations of TAM (A). Surviving fractions of MCF-7 treated with different concentrations of SIM (B). Combined cytotoxicity effect of I0 $\mu$ M TAM and different concentrations of SIM (0.5-2.5 $\mu \mathrm{M})$ in MCF-7 cells (C). Isobologram analysis of combination of TAM and SIM in MCF-7 cell line (D). Values are the means \pm SD of three independent experiments performed in triplicate. Statistical significance of results was analyzed using one-way ANOVA followed by Tukey's multiple comparison test. (a) Significantly different from the control group and (b) significantly different from the TAM-treated group at $P<0.05$.

of $10 \mu \mathrm{M}$ TAM and $2 \mu \mathrm{M}$ SIM was detected in MCF-7 with combination index, CI=1.18 (Figure 1D).

\section{The Combination Regimen Was Able To} Hinder The Oxidative Stress And Improve The Drop-In Antioxidant Markers In MCF-7 Cell Line

Treatment of TAM significantly increased the MDA level (Figure 2A) accompanied by significant reduction in the GSH content and SOD in MCF-7 breast cancer cell lines (Figures $2 \mathrm{C}$ and D). On the other hand, SIM alone showed a significant decrease in MDA (Figure 2A), accompanied with an increase in GSH and SOD activity in MCF-7 compared to control (Figures 2C and D). The combination of SIM and TAM produced significant inhibition in the MDA and NOx level by $49.2 \%$ and $23.1 \%$, respectively, compared to TAM-treated cells in MCF-7 (Figures 2A and B). The addition of SIM to TAM increased significantly, the GSH content by $253.8 \%$ and SOD activity by $53.7 \%$ compared to TAM treated cells (Figures 2C and D) in MFC-7cells.

\section{SIM Decreased Significantly The Glucose Uptake And LDH Induced By TAM In MCF-7 Cell Line}

Treatment of MCF-7 with TAM alone decreased the glucose consumption of MCF-7 cells, while treatment 
A MCF-7

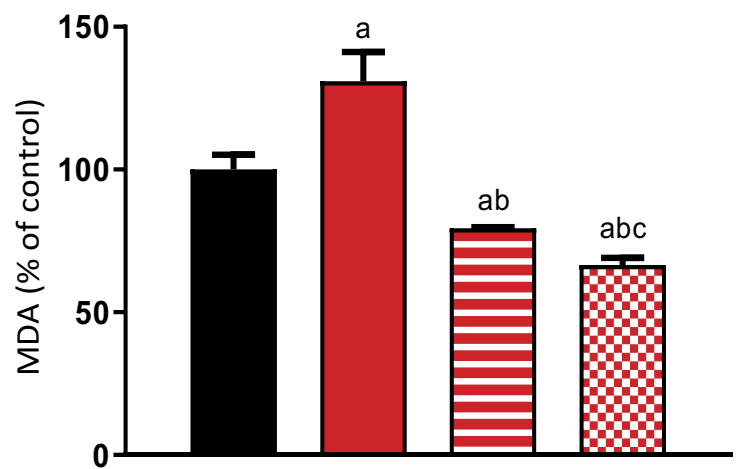

$\begin{array}{lllll}\operatorname{TAM} \mu \mathrm{M} & - & 10 & - & 10 \\ \operatorname{SIM} \mu \mathrm{M} & - & - & 2\end{array}$

C

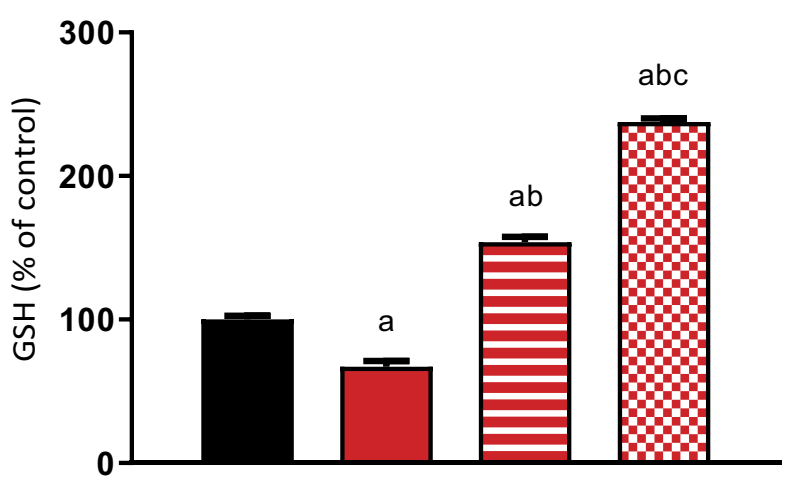

E

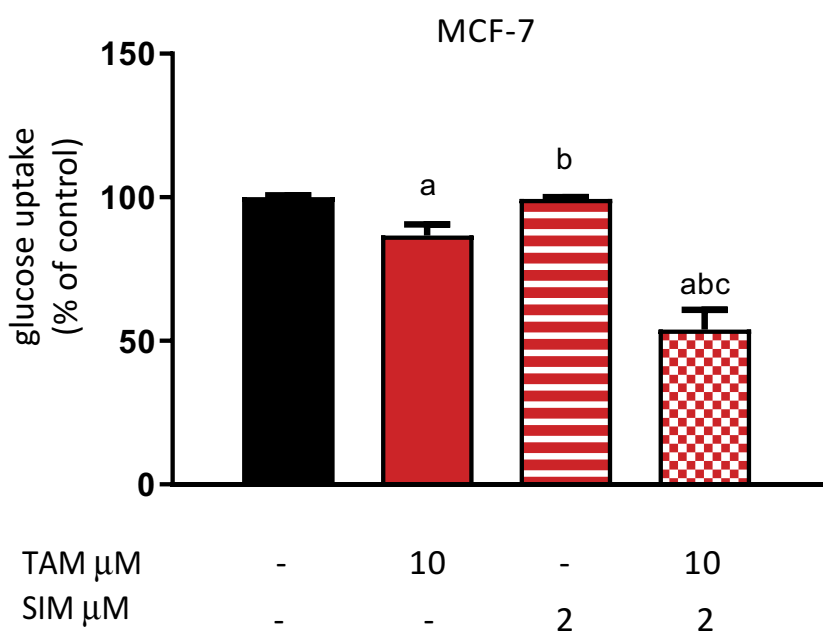

B

MCF-7

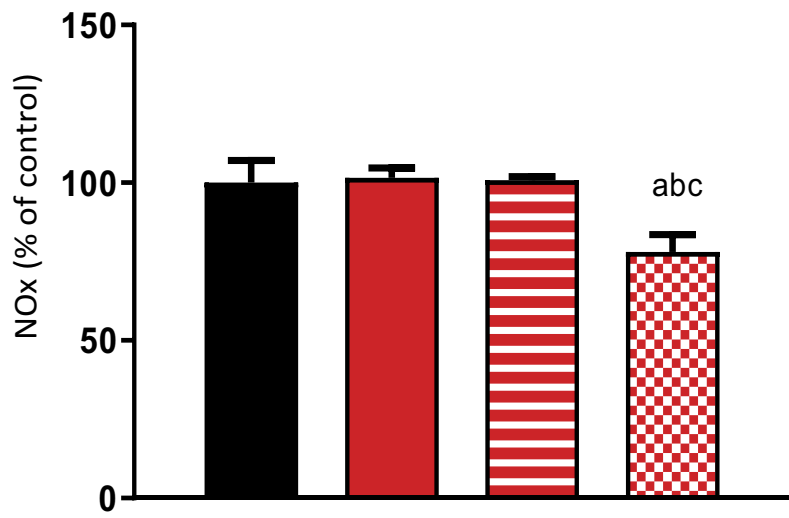

$\begin{array}{lcccc}\operatorname{TAM} \mu \mathrm{M} & - & 10 & - & 10 \\ \operatorname{SIM} \mu \mathrm{M} & - & - & 2 & 2\end{array}$

D

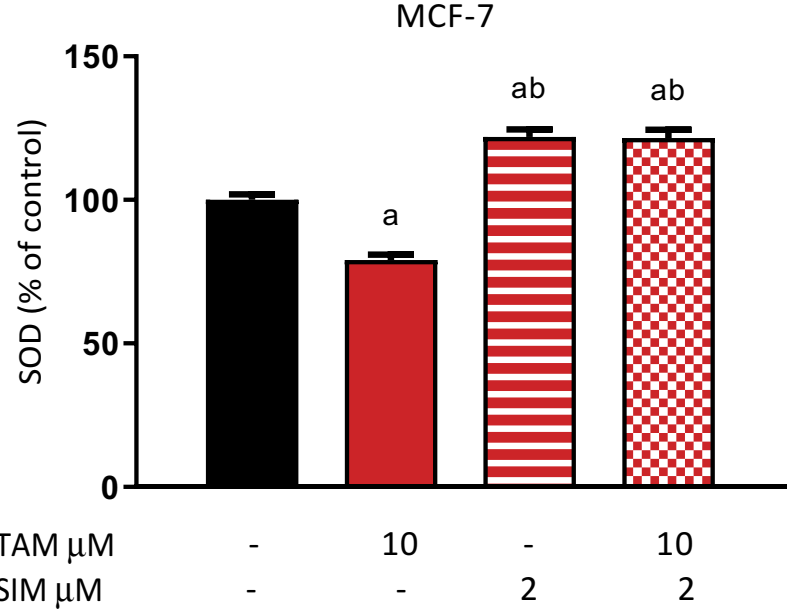

F

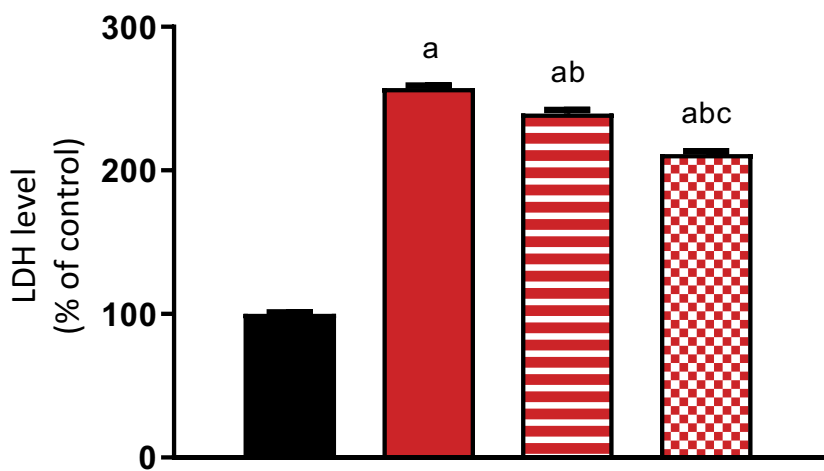

TAM $\mu \mathrm{M}$

10

10

$\mathrm{SIM} \mu \mathrm{M}$
MCF-7

2

Figure 2 Effect of treatment of TAM, SIM, and their combinations on oxidative stress markers, glucose uptake, and lactate dehydrogenase (LDH) in MCF-7 cells. MDA in MCF-7 cell line (A), NO in MCF-7 (B), GSH level in MCF-7 cell line (C), SOD in MCF-7 cell line (D). Glucose uptake (E), LDH level in media (F). Data were expressed as means \pm SD of three independent experiments. Statistical significance of results was analyzed using one-way ANOVA followed by Tukey's multiple comparison test. (a) Significantly different from the control group, (b) significantly different from TAM, and (c) significantly different from SIM at $P<0.05$. 
with SIM produced an insignificant difference from untreated controls. Moreover, the combination of SIM and TAM produced a significant decrease in glucose uptake compared to the untreated control and TAM treated groups (Figure 2E).

TAM alone significantly increased the released LDH level in the media in the breast cancer cell line compared to vehicle-treated cells. However, treatment with SIM significantly decreased LDH compared to control. The combination of TAM and SIM significantly decreased the LDH level by $17.8 \%$ in MCF-7 cells when compared to the TAM-treated group (Figure 2F).
The Combination Regimen Significantly Inhibited Bax, Bcl2 MRNA Expression, And Caspase-3 Activity In The MCF-7 Cell Line Either TAM or SIM individually significantly increased the expression of Bax and bcl-2 compared to control. On the other hand, the combination regimen of TAM and SIM caused a significant decrease in Bax and bcl-2 and nonsignificant Bax/bcl-2 compared to TAM (Figures $3 \mathrm{~A}$ and B). Treatment of MCF-7 cells with TAM produced a significant decrease in caspase-3 activity by $3.2 \%$ compared to control, while its combination
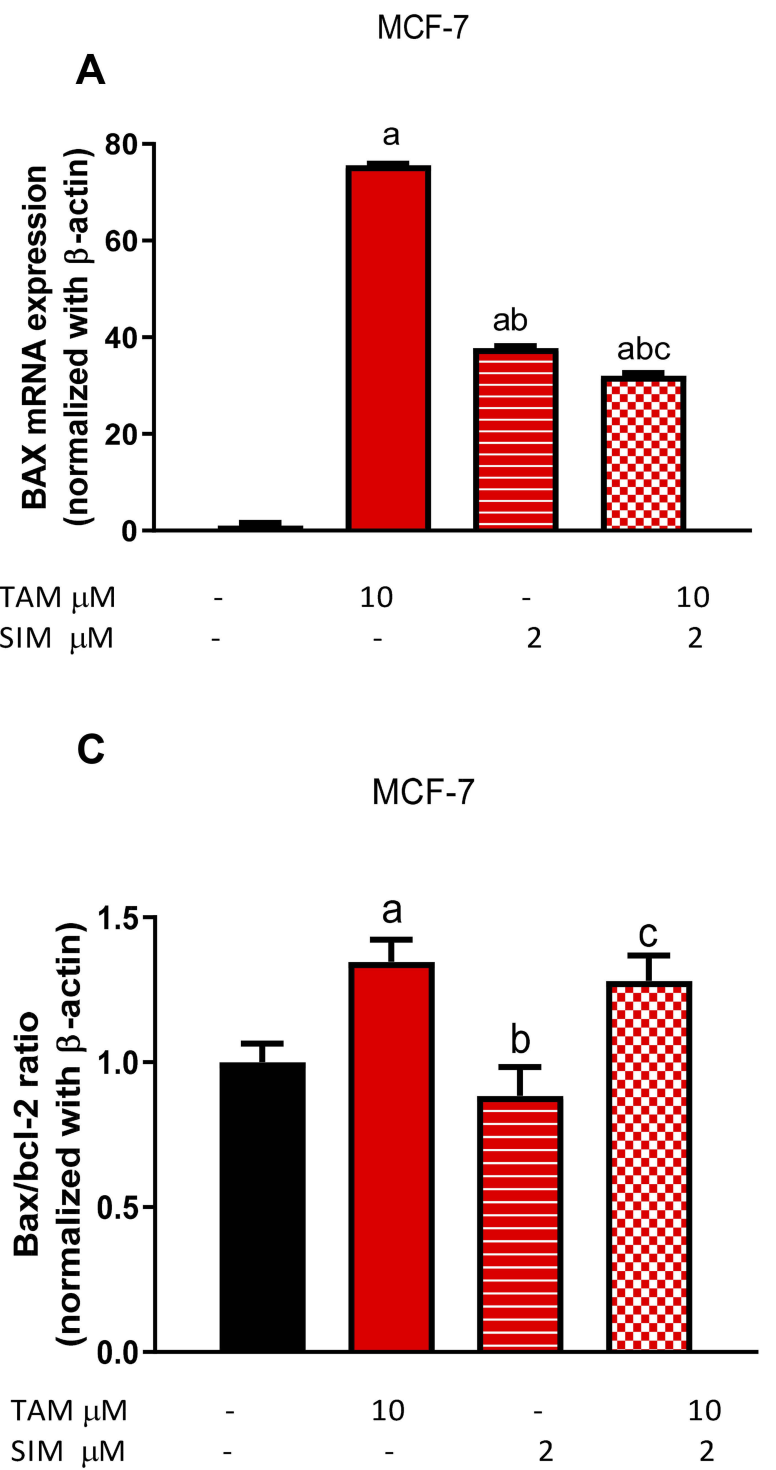
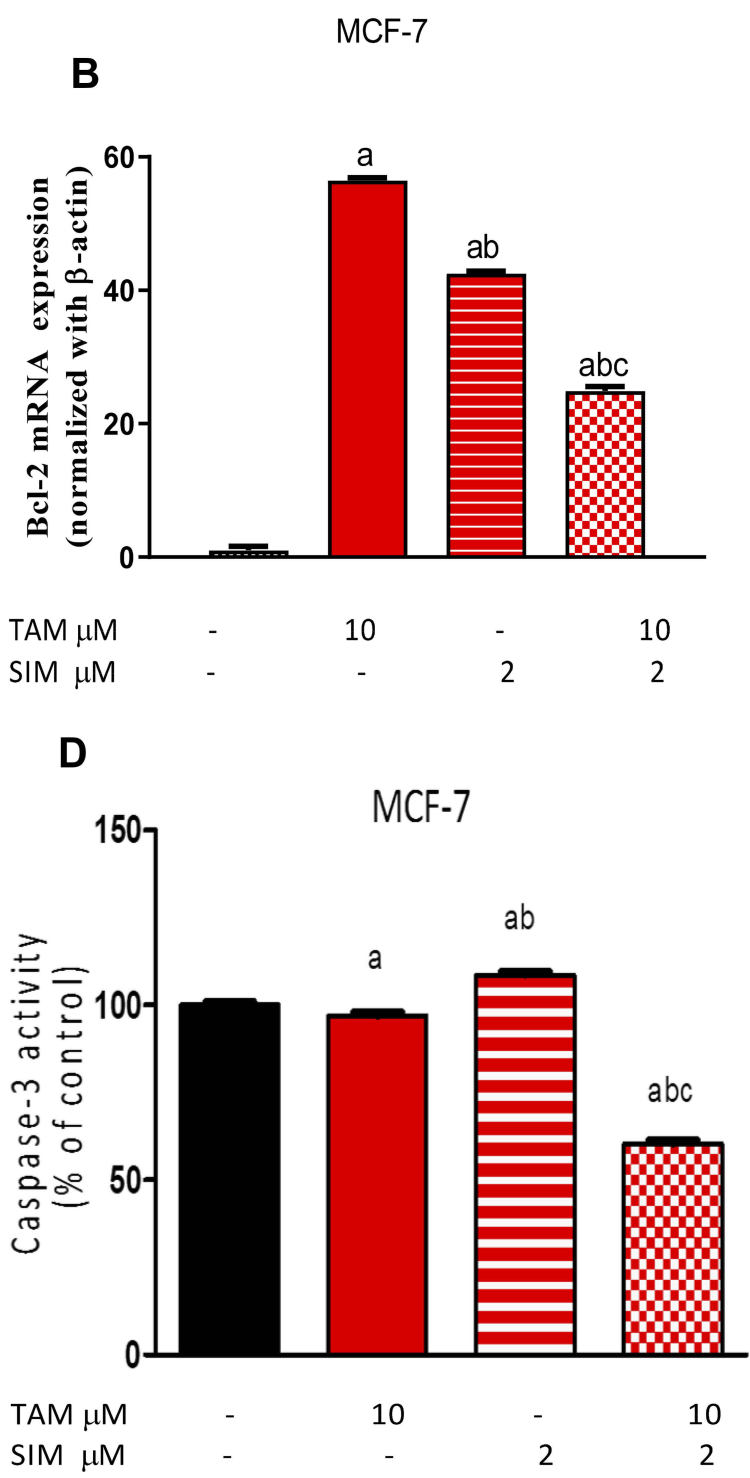

Figure 3 Effect of treatment of TAM, SIM, and their combinations of mRNA expression of Bax, bcl-2, Bax/bcl-2 ratio, and caspase 3 activity in MCF-7 cells. Bax expression (A), bcl-2 expression (B), Bax/bcl-2 ratio (C), Caspase 3 activity (D). Results are expressed as means \pm SD of two independent experiments performed in duplicate. Statistical significance of results was analyzed using one-way ANOVA followed by Tukey's multiple comparison test. (a) Significantly different from the control group, (b) significantly different from TAM, and (c) significantly different from SIM at $P<0.05$. 
with SIM resulted in a significant decrease by $37.7 \%$ as compared to the TAM treated group (Figure 3D). Furthermore, SIM significantly increased caspase-3 activity by $11.9 \%$ in MCF-7 cells compared to the TAM treated group (Figure 3D).

\section{The Combination Regimen Significantly Decreased The Total Apoptosis Ratio Compared To TAM}

Figure 4 shows the scatterplots and total apoptosis ratio (early and late apoptosis) for untreated MCF-7 cells, cells treated with TAM, cells treated with SIM, and cells treated with both drugs using flow cytometry. Treatment of TAM alone showed a significant increase in total apoptotic ratio, reaching $12.3 \%$ cell death. While SIM resulted in a significant increase $(11.1 \%)$ in the apoptotic ratio. On the other hand, treatment of both TAM and SIM produced a significant decrease in apoptotic ratio $(9.45 \%)$ compared to TAM.

\section{Protein Expression Of Bcl- 2, Bax, And NF- $\kappa B$, By Immunohistochemically}

TAM increased MRNA expression of bcl-2, Bax, and the ratio of Bax/bcl-2 compared to control. In addition, SIM alone increased bcl-2 and Bax while there was an insignificant difference of Bax/bcl-2 compared to control. The combination treatment of TAM and SIM produced an insignificant change in Bax/bcl-2 ratio compared to the TAM treated group.

The protein expression of bcl-2 increased in TAM (++) and SIM $(+)$ treated cells, while the expression of Bax was increased $(+)$ in TAM and SIM (0) treated MCF-7. The combination treatment produced a significant decrease in both bcl-2 or Bax relative to TAM. Examination of MCF-7 cells showed strongly positive staining for NF- $\kappa B$ in the TAM treated group $(+++)$, while SIM and the combination regimen showed weak staining $(+)$ (Figure 5).

\section{The Combination Regimen Inhibited MMP-2 And 9, And VEGF In MCF7 Breast Cancer Cell Line}

Either TAM or SIM treatment increased activity of MMP-2 and 9 in the MCF-7 cell line. However, the combination of SIM and TAM inhibited the activity of MMPs compared to TAM treated cells of the cell line (Figure 6A).

Incubation of MCF-7 cells with TAM significantly decreased in the level of VEGF by $82.2 \%$ compared to the control treated group. SIM alone caused a significant decrease in VEGF by $20 \%$, while a combination with TAM produced a significant decrease compared to the TAM treated group (Figure 6B).
A
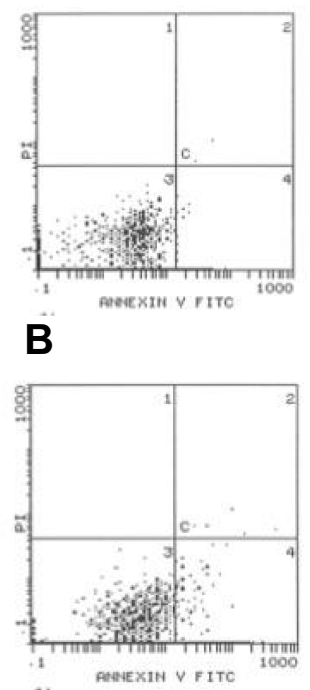

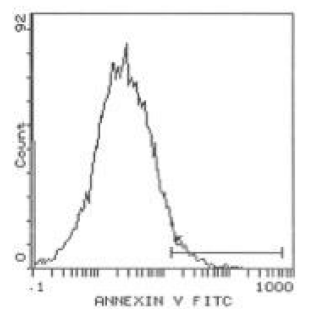

PHAEXIN Y FITC

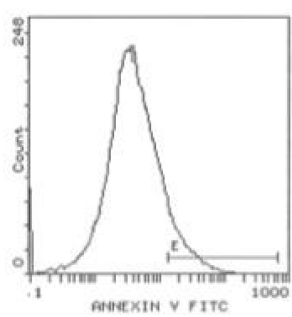

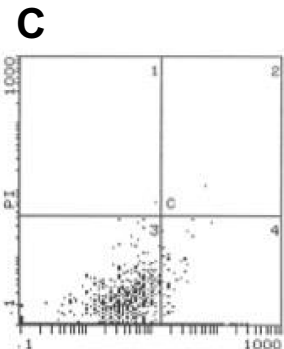

ATHEXIN Y FITO
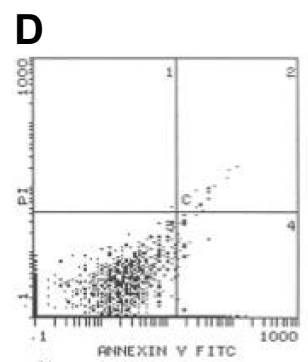
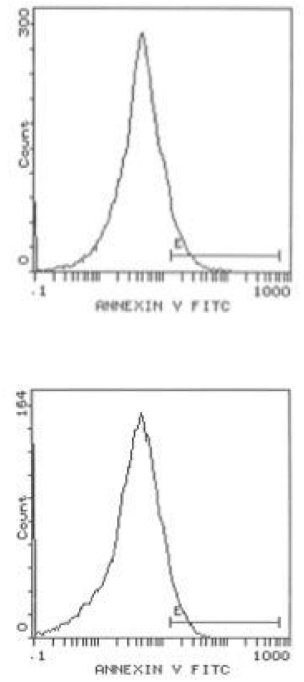

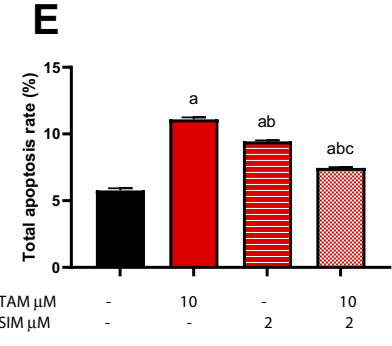

Figure 4 Effect of treatment of TAM, SIM, and their combinations on total apoptotic ratio using flow cytometry in MCF-7 cells. Flow cytometry scatterplots for (A) control, (B) TAM, (C) SIM, (D) combination, and (E) quantitative analysis of the total apoptosis rate. Results are expressed as means \pm SD of two independent experiments performed in duplicate. Statistical significance of results was analyzed using one-way ANOVA followed by Tukey's multiple comparison test. (a) Significantly different from the control group, (b) significantly different from TAM, and (c) significantly different from SIM at $P<0.05$. 


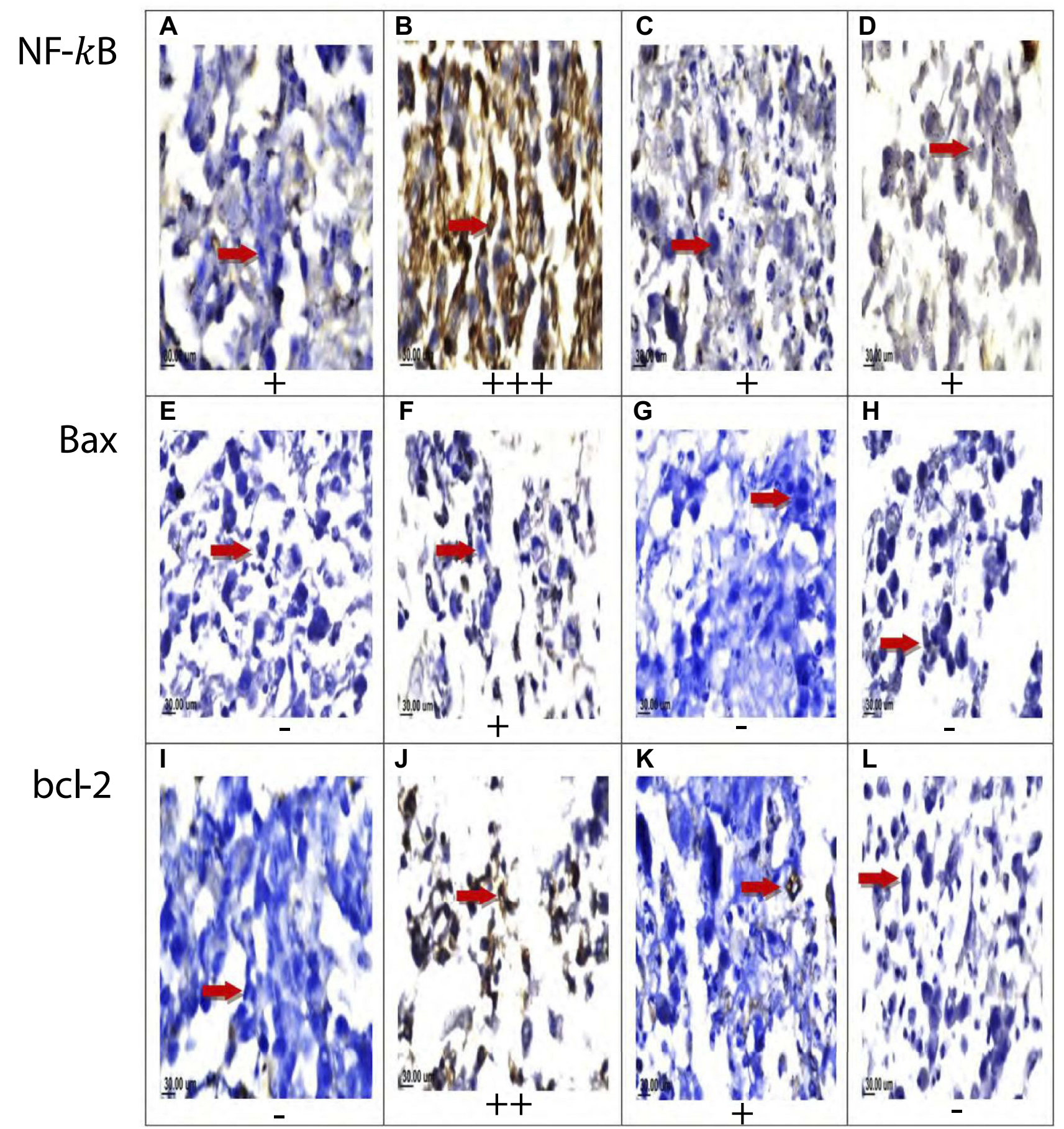

Figure 5 Effect of TAM, SIM, and their combinations on the expression levels of NF-kB, Bax, and bcl-2 in MCF-7 cell lines. Immunohistochemical staining of NF-kB of control non-treated group (A), TAM treated group (B), SIM treated group (C), and combination treated group(D). Immunohistochemical staining of Bax for control group (E), TAM treated group (F), SIM treated group (G), and combination treated group (H). Immunohistochemical staining of bcl-2 for control group (I), TAM treated group (J), SIM treated group (K), and combination group (L) $(\times 160)$.

\section{SIM Did Not Affect Cellular Uptake Of} TAM In The Breast Cancer Cell Line

By studying the effect of time, a significant increase in TAM uptake was shown in both TAM \& TAM+SIM treated groups up to 24 hours followed by a significant drop at 48 hours in the MCF-7 cell line $(P=0.013)$ (Figure 7). By studying group interaction, although MCF-7 showed higher levels of TAM in the TAM + SIM group from 2 hours up to 24 hours (significant only at $2(P=0.012)$ and 6 hours $(P=<0.001))$, yet at 48 


\section{A}

Control

TAM

MMP-9 (92 KDa)

MMP-2 (72 KDa)
B
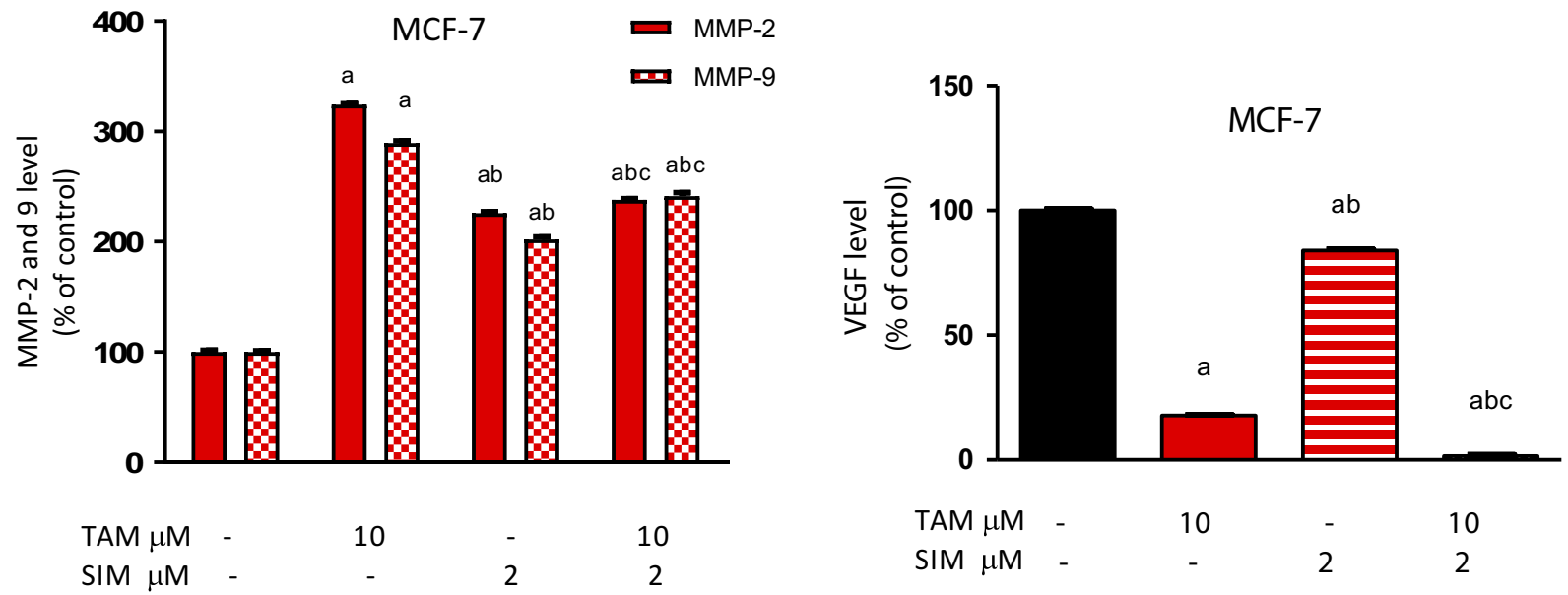

Figure 6 Effect of treatment of TAM, SIM, and their combinations on the levels of VEGF and MMP-2 and 9 using gelatin zymography on MCF-7 cells. MMP-2 and 9 represented as a percentage of control (A), Level of VEGF (B), the analysis of image was done by image $j$ software. The results are expressed as the mean \pm SD of two separate experiments. Statistical significance of the result was analyzed by one-way ANOVA followed by Tukey multiple comparison test. (a) Significantly different from its respective control, (b) significantly different from TAM, and (c) significantly different from SIM at $P<0.05$.

hours a significant increase was shown in the TAM group as compared to TAM+SIM $(P=<0.001)$, but the $P$-value for interaction was non-significant borderline $(p=0.09)$ (Figure 7).

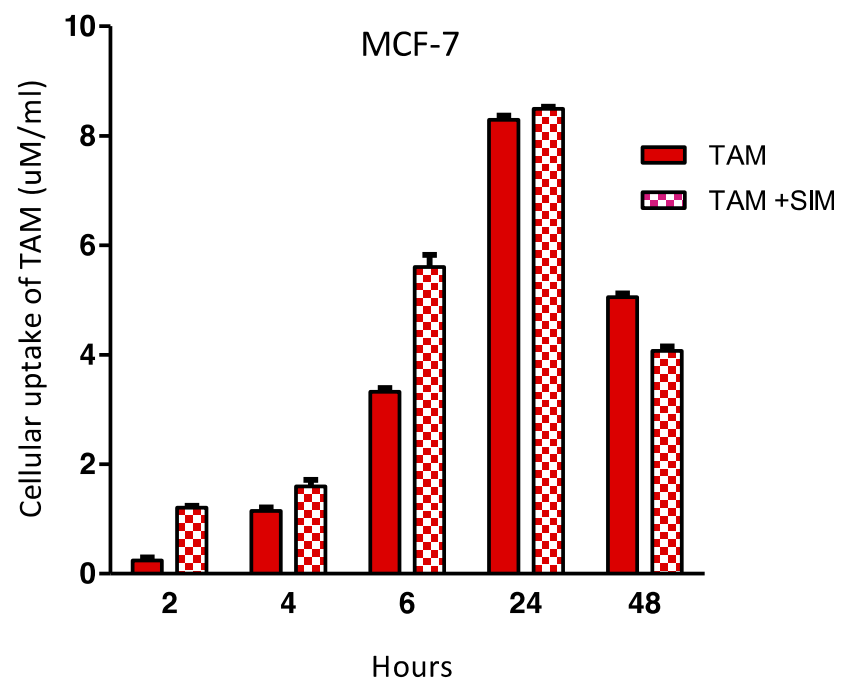

Figure 7 Effect of treatment of SIM on cellular uptake of TAM after different time intervals in the MCF-7 cell line. The results are expressed as the mean \pm SD of two separate experiments performed in duplicate. Statistical significance of the result was analyzed by ANOVA with repeated and mixed model followed by Bonferroni test for adjustment for multiple comparisons was used for comparison between two groups in TAM uptake. A value of 0.05 or less was taken as a criterion for a statistically significant difference.

\section{In Vivo Result}

In Vivo, SIM Did Not Significantly Reduce Tumor Volume Induced By TAM

The volume of solid tumor was decreased by $59 \%$ in the TAM treated group compared to the control group; however, the SIM treated group and the combination regimen treated group were not significantly different from the effect of the TAM treated group (Figure 8).

\section{In Vivo, SIM Significantly Decreased The Oxidative Stress Of TAM}

TAM increased significantly MDA and NOx accompanied by a significant decrease in GSH and SOD activity. Compared to the TAM treated group, the combination treatment caused a significant decrease in the level of MDA by $30 \%$, and NOx by $11.9 \%$, while there was an increase in SOD activity by $15.6 \%$ (Figure 9 ).

\section{Immunohistochemical Results}

Histopathological examination of the mouse solid tumor in all the studied groups showed necrosis and apoptosis as presented in solid EAC tumor of control mice (A). EAC tumor-bearing mice treated with TAM $(2.5 \mathrm{mg} / \mathrm{kg})$ showing severe necrosis and apoptosis (B), SIM (2 mg/kg) (C), and combinations treated (TAM+SIM) showing moderate necrosis and apoptosis (D) (Figure 10). All the treatment 


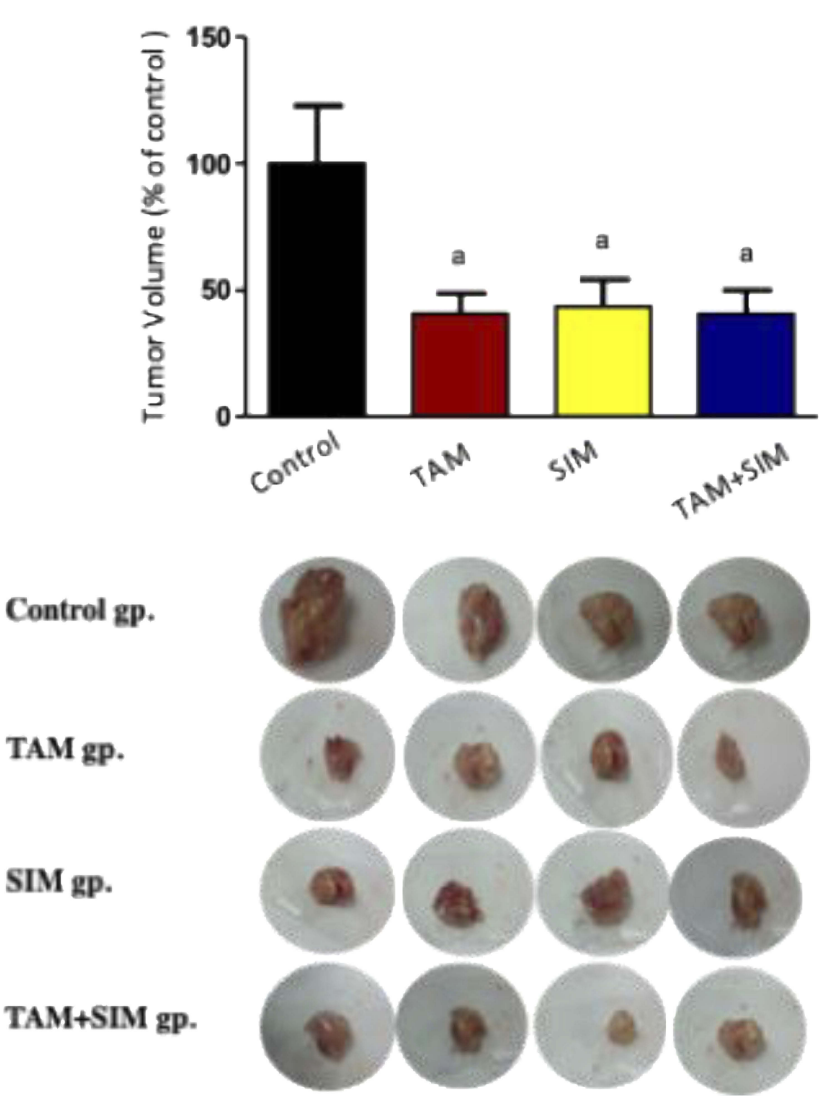

Figure 8 Effect of TAM $(2.5 \mathrm{mg} / \mathrm{kg})$, SIM $(2 \mathrm{mg} / \mathrm{kg})$, and their combination on tumor volume of EAC-bearing mice. Values were given as mean \pm SD of $n=6$. Statistical significance of the result was analyzed by one-way ANOVA followed by Tukey multiple comparison test. (a) Significantly different from the control group at $P<0.05$.

regimens lowered the level of TNF- $\alpha$ expression to different extent when compared to the control group. Moreover, in TAM and the combination treated groups, the expression of NF- $\mathrm{kB}$ was less than SIM treatment alone, as shown in Figure 11.

\section{Discussion}

Tamoxifen is typically prescribed as an adjuvant therapy for primary ER+ breast cancer and neoadjuvant endocrine therapy for selected patients with hormonal-locally advanced breast cancer. ${ }^{30}$ The results of this study showed that TAM treatment inhibited cellular proliferation, by a significant increase in ROS, and LDH leakage in MCF-7. TAM has an anti-proliferative effect mediated by inhibiting the activities of estrogen and/or by estrogenindependent manners. ${ }^{31}$ The increase in oxidative stress was suggested as a prerequisite leading to cell death, and the reduction in antioxidant activity sensitizes the cells to ROS-induced cell death. ${ }^{32}$ Moreover, the leakage of LDH into the culture medium is a well-known indicator of necrotic cell death or damage to the cell membrane of $\mathrm{BC}$ cells treated with TAM. ${ }^{33}$ Our results registered a significant decrease in apoptotic cell death manifested by a decrease in caspase-3 activity and overexpression of bcl-2 was recorded by TAM. It was disclosed that cells with deficient caspase-3, such as MCF-7, can undergo apoptosis. ${ }^{34} \mathrm{~A}$ form of programmed necrosis, called necroptosis or inflammatory cell death, has been recognized in a caspase-independent fashion as an alternative form of programmed cell death. This modality of cell death can be either triggered independently of apoptosis or engaged under conditions of caspase inhibition. ${ }^{35}$ Both necroptosis and necrosis can serve as a cell-death backup to apoptosis when the apoptosis signaling is blocked by endogenous or exogenous factors. Moreover, cancer cells may depend on bcl-2, or related members to prevent apoptosis that may modulate the sensitivity of $\mathrm{BC}$ cells. ${ }^{36}$

The enhanced glucose uptake is a well-known metabolic hallmark of cancer cells. ${ }^{37}$ Data of the present study displayed a decrease in glucose consumption, VEGF, and NF- $\kappa$ B, while an increase in MMP2 \& 9 in MCF-7 cells by TAM was documented. Similar to our results, tamoxifen decreased the rate of glucose consumption through inhibition of glycolysis in MCF-7 by inhibiting estrogeninduced expression of glucose transporter- $1 .{ }^{38}$ In addition, TAM decreases glucose uptake and causes a significant increase in glycated hemoglobin HbA1c in C57BL/6NTac mice. ${ }^{39}$ In addition, VEGF and MMPs are critical markers in malignant tumors for angiogenesis and metastases. ${ }^{40}$ TAM was reported to decrease angiogenic and metastatic potential by diminished VEGF release. ${ }^{41}$ TAM was found to significantly increased MMP-2/MMP-9 activity and endostatin levels in human $\mathrm{BC}$, suggesting a possible role of MMP modulation associated with a generation of anti-angiogenic fragments in the therapeutic effect of TAM in $\mathrm{BC} .^{42,43}$ It was suggested that inhibition of NF- $\kappa \mathrm{B}$ may be an effective treatment strategy to limit the progression of $\mathrm{BC}$ and development of resistance via activation of the PI3K/Akt signaling pathway. ${ }^{44}$

Statins, the 3-hydroxy-3-methylglutaryl (HMG)-CoA reductase inhibitors, reduce not only serum cholesterol levels but also mevalonate synthesis. Mevalonate is a precursor of several major products regulating the cell cycle, signal transduction of several membrane proteins involved in cell proliferation, differentiation, and apoptosis. $^{12,45}$ Our results showed that treatment of MCF-7 cells with SIM significantly decreased the cell survival accompanied with a significant increase in 
A

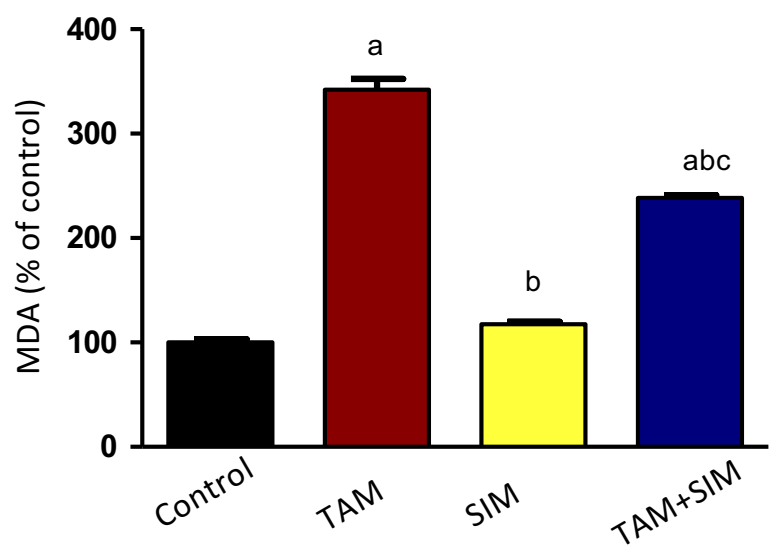

C

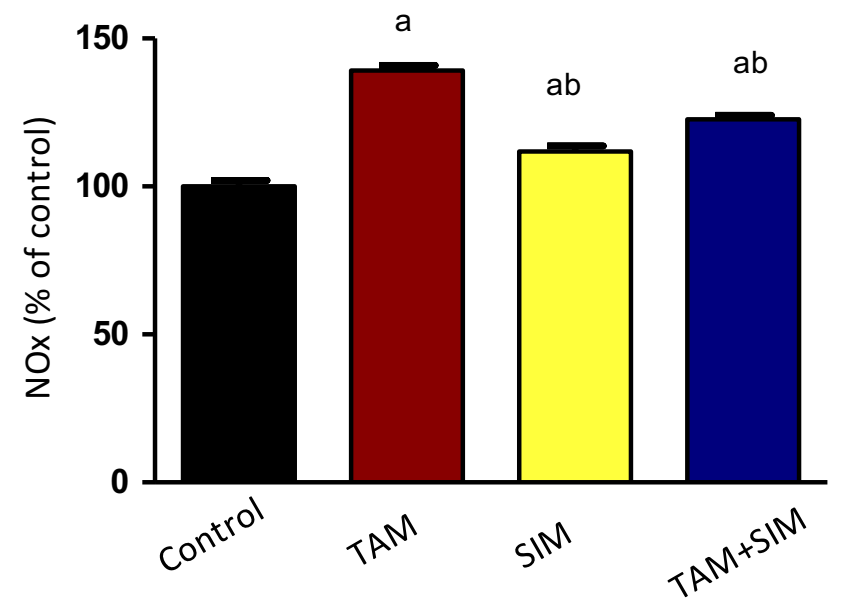

B

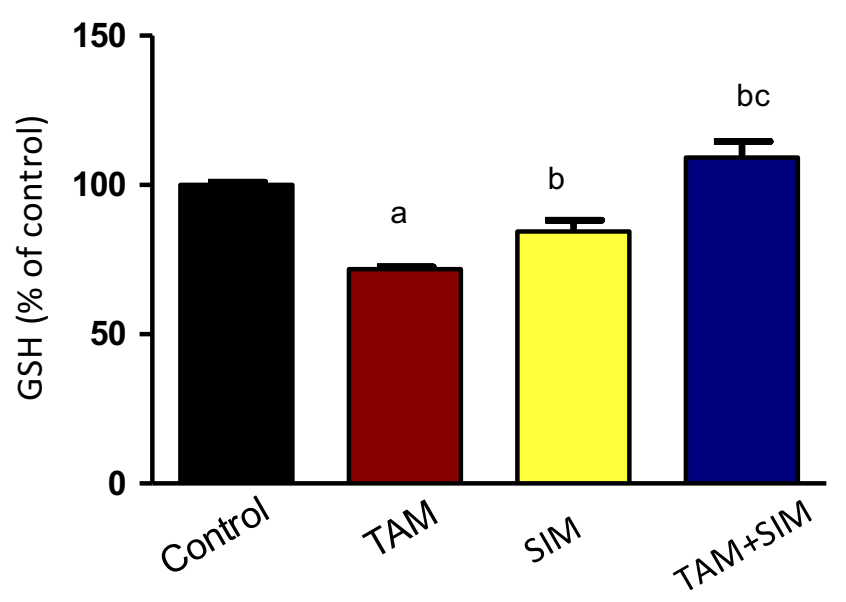

D

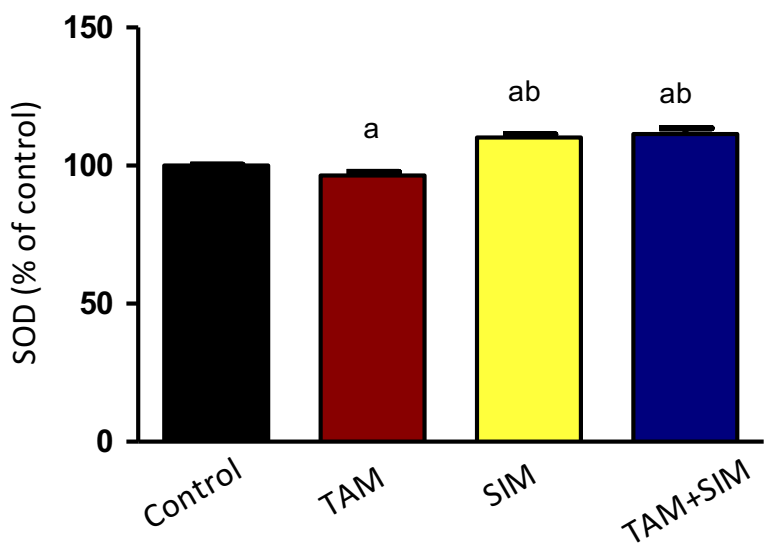

Figure 9 Effect of TAM, SIM, and their combinations on oxidative stress markers of solid EAC of mice. MDA (A), GSH (B), SOD (C), and NOx (D). Results are expressed as means \pm SD of tumor volume from six mice. Statistical significance of the result was analyzed by one-way ANOVA followed by Tukey multiple comparison test. (a) Significantly different from the control group, (b) significantly different from the TAM group, and (c) significantly different from SIM, at $P<0.05$.

caspase-3, and LDH leakage while it inhibited oxidative stress markers. Similarly, SIM was reported to increase the apoptotic markers by blocking cell proliferation in the $\mathrm{G} 0$ / G1 phase, low expression of $\mathrm{Ki} \mathrm{67,} \mathrm{and} \mathrm{by} \mathrm{an} \mathrm{increase} \mathrm{in}$ the protein tyrosine phosphorylation leading to apoptosis. ${ }^{45,46}$ Also, SIM induced inhibition in breast cancer cells due to apoptosis via involvement of JNK independent of their ER or p53 expression status and necrotic cell death. ${ }^{47}$ In addition, SIM downregulates the retinoblastoma (RB) signals and alters the expression of cyclin D1, p27, and MCM7 and upregulates $\gamma \mathrm{H} 2 \mathrm{AX}$, leading to DNA damage in TAM resistant breast cancer cells by. ${ }^{16}$ Moreover, SIM reduces breast cancer cell proliferation by deactivating $\mathrm{NF}-\kappa \mathrm{B}$, inhibiting the expression of the antiapoptotic protein bcl-xl, while increasing transcription of phosphatase and tensin homolog (PTEN), especially in cell lines with constitutively active RAS or overexpressed HER2. ${ }^{48,49}$ In accordance with our results, Taha et al ${ }^{50}$ described a significant increase in $\mathrm{LDH}$ release when C2C12 cells were exposed to statins. It was documented that SIM increases the cellular defense against ROS and reduces ischemia-reperfusion-evoked LDH release through its antioxidant effect. ${ }^{51,52}$ In addition, statin treatment induced SOD and catalase activities in triple negative breast cancer (TNBC) cells. ${ }^{53}$ Moreover it was demonstrated that statins influenced disease free survival for inflammatory breast cancer (IBC) patients. ${ }^{54}$ Contrary to our results SIM caused the formation of superoxide, implicating oxidative stress as a contributing factor in their cytotoxic activity. ${ }^{47}$ Our data showed that, compared to 
A

\section{B}
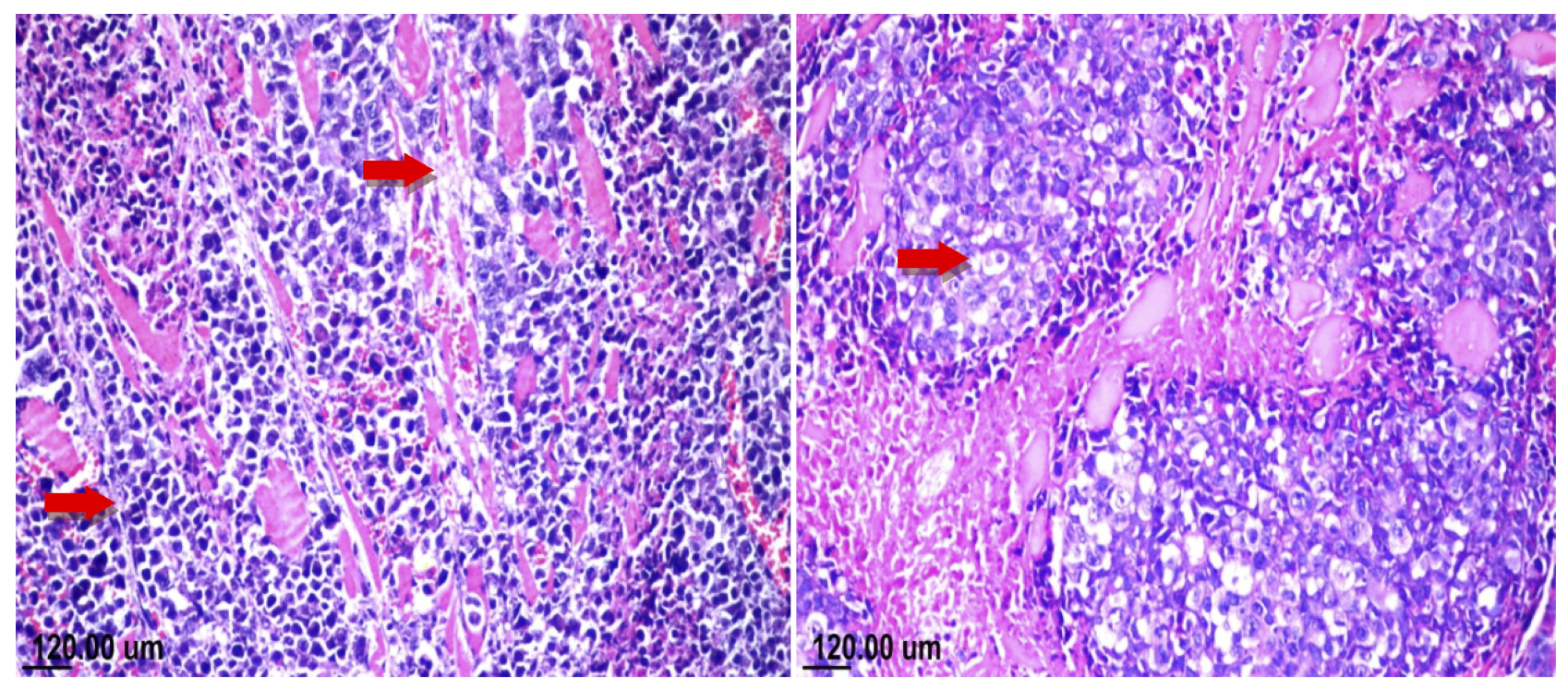

C

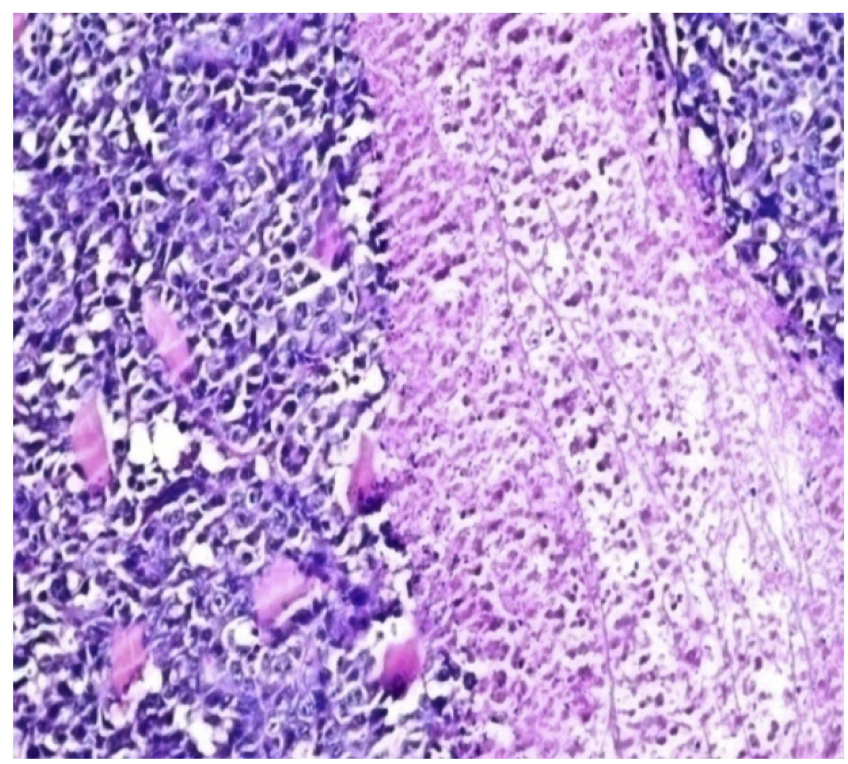

\section{D}

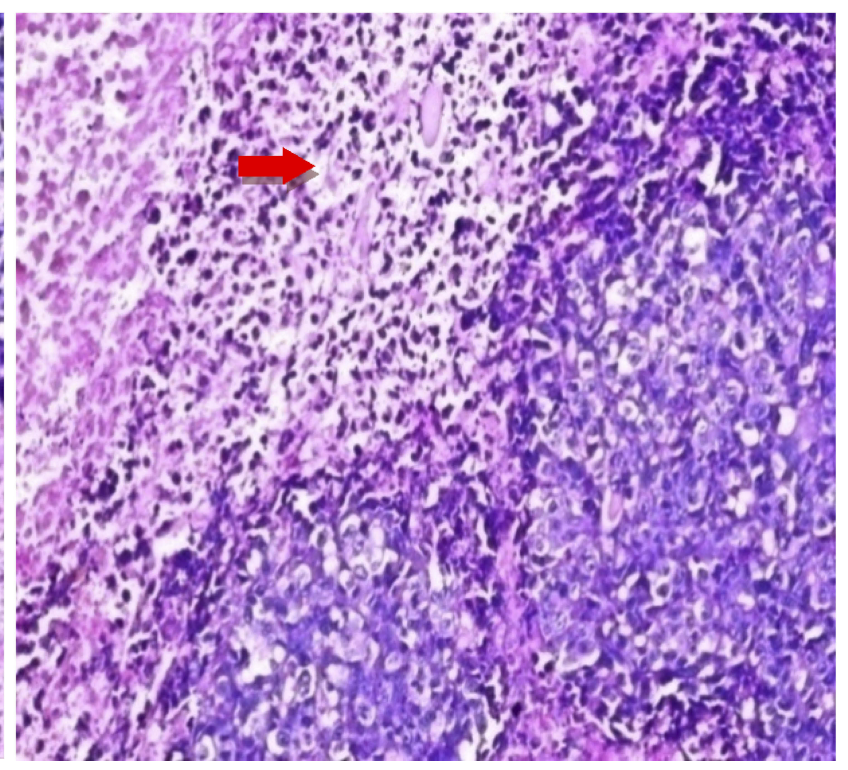

Figure 10 Photomicrographs of solid tumor of EAC. Sections stained by H\&E ( $\times 40)$. Sections taken from solid EAC tumor of control mice showing mild necrosis and apoptosis (A), sections taken from solid EAC tumor-bearing mice treated with TAM (2.5 mg/kg) showing severe necrosis and apoptosis (B), SIM (2 mg/kg) (C), and combinations (TAM+SIM) showing moderate necrosis and apoptosis (D).

the TAM treated group, SIM did not affect glucose consumption, while it decreased, NF- $\kappa \mathrm{B}, \mathrm{MMP} 2 \&$ 9, and VEGV of MCF-7 cells. In clinical trials, statin was found to impair cellular glucose uptake and induce hyperglycemia. ${ }^{55}$ Malenda et $\mathrm{al}^{56}$ indicated that statins could effectively inhibit glucose uptake by tumor cells, thereby impairing adaptation of tumor cells to microenvironmental conditions associated with tumor progression. It was suggested that the statin inhibited invasion and metastasis in the aggressive $\mathrm{BC}$ cell line MDA-MB 231 via blockade of the mevalonate pathway, and inhibition of both MMP-2 and MMP-9. ${ }^{57}$

The present data revealed that treatment of MCF-7 with combination of SIM and TAM resulted in antagonistic drug interaction. This antagonistic effect was in harmony with the detected decrease in apoptotic markers, mainly caspase 3 activity, and the decrease in the protein expression of Bax and bcl-2 compared to TAM-treated cells. Also in vivo study displayed that the administration of the combination of TAM and SIM resulted in an insignificant decrease in the tumor 
TNF-a

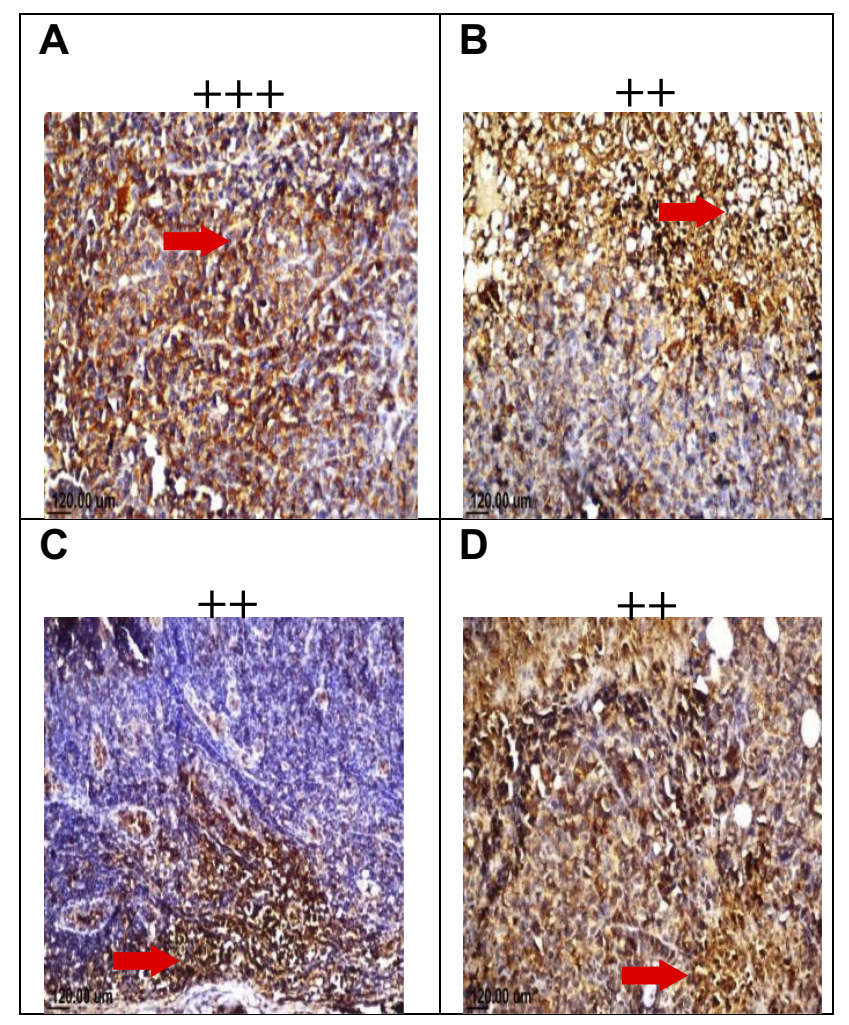

NF- ${ }_{k} B$

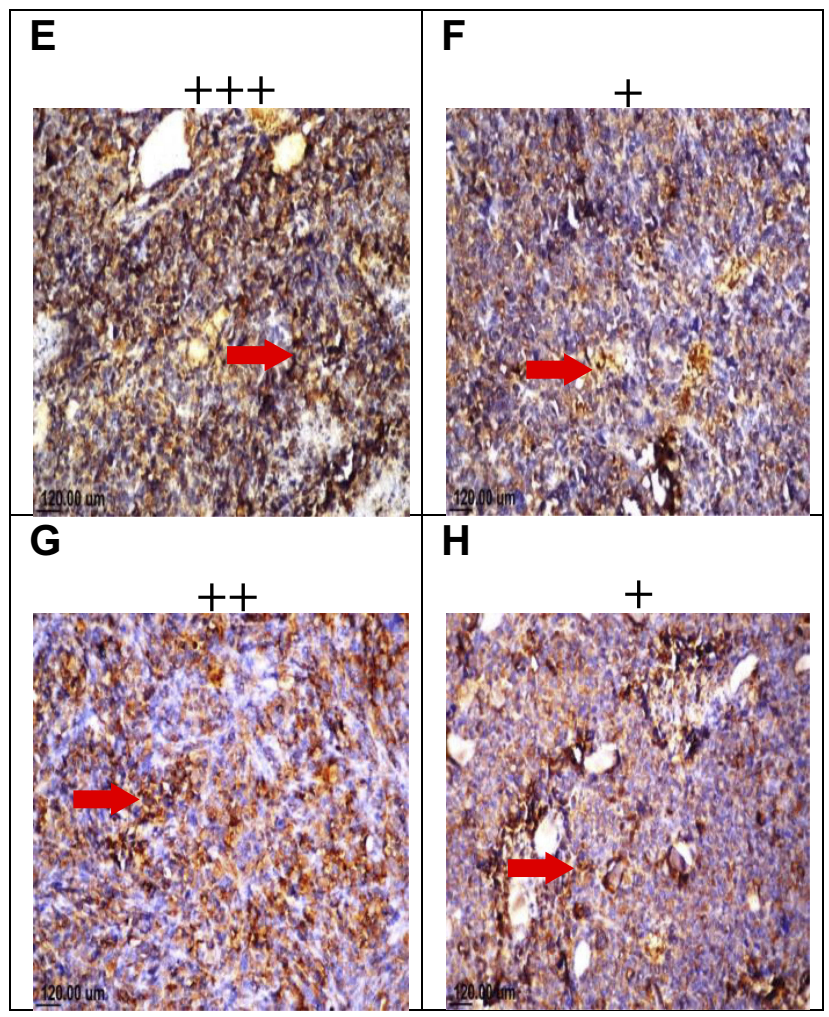

Figure II Effect of treatment of TAM, SIM, and their combinations on TNF- $\alpha$ and NF- $\kappa B$ expression in EAC solid tumor. Immunohistochemical staining of TNF- $\alpha$ in EAC solid tumor sections ( $\times 40)$ control (A), TAM (2.5 mg/kg) (B), SIM (2 mg/kg) (C), and combination (D). Immunohistochemical staining of NF-kB in EAC solid tumor sections (x40). Control (E), TAM (2.5 mg/kg) (F), SIM (2 mg/kg) (G), and combination (H).

volume compared to TAM treated mice. On the other hand, and contrary to our results, the combination of exemestane (an aromatase inhibitor) and simvastatin generated synergistic effects on MCF-7 ER+ breast cancer cells. ${ }^{58}$ Also, SIM in combination with doxorubicin suppress the prosurvival ERK1/2 pathway in a $\mathrm{Ca}^{2+}$ independent and $\mathrm{Ca}^{2+}$ dependent manner. ${ }^{59,60}$ Moreover, Liang et al ${ }^{61}$ found that the combination of SIM and TAM suppressed the growth, induced apoptosis, and inhibited xenograft growth and subsequently inducing DNA damage in TAM-resistant breast cancer cells. The authors concluded that the antitumor effect of SIM might be contributed to mechanism dependent of blocking of the hormonal receptor. The controversy between the results of our study and the previous ones may be due to either differences in the drug in combination with TAM or in the cell line type. In the first two studies, the authors used exemestane, ${ }^{58}$ an aromatase inhibitor, or doxorubicin ${ }^{59}$ that are of different classes and mechanisms from TAM. In the study of Liang et $\mathrm{al},{ }^{61}$ the cell line was TAM resistant MCF-7, which is biologically and metabolically different from the TAMsensitive one. It was reported that statins have an impact on the outcomes of patients with aggressive triple negative breast cancer. ${ }^{62}$ Breast cancer cells differ in their individual sensitivity to SIM, ER+ breast cancer cell lines, MCF-7, and T47 D, had marginal cytotoxicity compared to $60 \%$ in the triple negative MDA-MB-231 and MDA-MB-468 breast cells. There was upregulation of cholesterol limiting enzyme, HMGCR mRNA, and protein expression by up to 6-fold in the statinresistant cells lines MCF7 and T47D, but no alteration of HMGCR was detected in the statin-sensitive MDA-MB-231 and MDA-MB-468 cells. ${ }^{63}$ SIM can induce cleavage of the sterol-regulatory element-binding protein (SREBP)-2, a transcriptional activator of the HMGCR, in T47D and MCF-7 cells leading to its resistance. ${ }^{64}$ Moreover, in parallel to the increase in HMGCR, SIM significantly upregulates the expression of oncogene SND1 mRNA in hepatoma cells that interact with the genomic DNA leading to modulation of cell growth, oncogenic transformation, viral infection, and metabolic regulation. ${ }^{65}$ Moreover, statin may interfere with the antiestrogenic effect of TAM and activates estrogen receptor $\alpha(E R \alpha)$ and therefore induces potential disruption of normal endocrine function. It was uncovered that activation of 
estrogen receptor $\alpha(\mathrm{ER} \alpha)$ enhances the in vitro proliferation, invasion, and migration of neuroblastoma cells. ${ }^{66}$ SIM increases estrogen receptor-alpha (ER- $\alpha)$ protein levels in murine bone marrow stromal cells. ${ }^{67}$ Therefore, the differences in drug interaction between the different cell lines could be attributed to the differences in biological functions, the proteins involved in cell growth stimulation, anti-apoptosis mechanisms, and carcinogenesis between the different cell lines. Our data showed that SIM in combination with TAM succeeded in decreasing the oxidative stress, VEGF, MPP2 \& 9, and LDH leakage-induced by TAM. In addition, the treatment of mice bearing EAC by the combination of TAM with SIM resulted in a significant decrease in MDA, TNF- $\alpha, \mathrm{NF}-\kappa \mathrm{B}$, and VEGF compared to the TAM treatment group. SIM was reported to have an antioxidant effect; it decreased free radical production and increased the level of glutathione content. ${ }^{53}$ However, Malenda et $\mathrm{al}^{56}$ and Nowis et $\mathrm{al}^{55}$ found statins impair glucose uptake in tumor cells by inducing cholesterol dependent conformational changes in GLUTs.

The vascular endothelial growth factor is one of the important angiogenic factors secreted by the tumor cells, which stimulates tumor neo-angiogenesis and vascular permeability. ${ }^{40}$ Recently, it has been recognized that urokinase plasminogen activator is one of the key regulators of the metastatic processes related to human cancer. It cleaves and activates the matrix metalloproteinases (MMPs) that break down the extracellular matrix (ECM) of cancer cells and, in turn, promote the invasion and migration of human cancers. ${ }^{68}$ Our results are in agreement with Wang et al ${ }^{51}$ and Coimbra et $\mathrm{al}^{57}$, who found that statins inhibited angiogenesis and have a direct effect on tumor AMP kinase signaling, which impedes downstream hypoxia-inducible factor-1 $\alpha$ (HIF-1 $\alpha$ )-induced angiogenesis. $^{52}$ Matrix metalloproteinases (MMPs) play significant roles in tumor growth, and metastasis by degradation of collagen and other extracellular matrix components. ${ }^{69}$ SIM inhibited MMP-9 expression in osteoblastic cells and HT1080 fibrosarcoma cells. ${ }^{70}$ In addition, Kang et $\mathrm{al}^{71}$ reported that SIM down-regulates H-Ras-induced MMP-9 expression and suppressed MMP-9 but not MMP-2 expression in human leukemia U937 and KU812 cells. ${ }^{72}$

In conclusion, the combination regimen of TAM and SIM showed antagonistic drug interaction in MCF-7 breast cancer cells and an insignificant change in tumor volume of mice bearing EAC model. However, it displayed a favorable effect against angiogenesis, metastasis, and inflammation both in vitro and in vivo. No doubt that further studies are required to confirm these results in preclinical and clinical settings.

\section{Acknowledgment}

The authors of the manuscript acknowledge the National Cancer Institute, Cairo University for providing the facility and supporting this work.

\section{Author Contributions}

All authors contributed to data analysis, drafting and revising the article, gave final approval of the version to be published, and agree to be accountable for all aspects of the work.

\section{Disclosure}

The authors of the manuscript disclose that they have no competing financial interests or personal relationships that could have appeared to influence the work reported in this paper.

\section{References}

1. Siegel R, Miller K, Jemal A. Cancer statistics, 2018. Cancer J Clin. 2018;68:7-30.

2. Lim E, Metzger-Filho O, Winer EP. The natural history of hormone receptor-positive breast cancer. Oncology. 2012;26(8):688-694.

3. Dellapasqua S, Colleoni M, Gelber RD, Goldhirsch A. Adjuvant endocrine therapy for premenopausal women with early breast cancer. $J$ Clin Oncol. 2005;23(8):1736-1750. doi:10.1200/JCO.2005.11.050

4. Aesoy R, Sanchez BC, Norum JH, Lewensohn R, Viktorsson K, Linderholm B. An autocrine VEGF/VEGFR2 and p38 signaling loop confers resistance to 4- hydroxytamoxifen in MCF-7 breast cancer cells. Mol Cancer Res. 2008;6:1630-1638. doi:10.1158/154 1-7786.MCR-07-2172

5. Lagadec C, Adriaenssens E, Toillon RA, et al. Tamoxifen and trail synergistically induce apoptosis in breast cancer cells. Oncogene. 2008;27:1472-1477. doi:10.1038/sj.onc.1210749

6. Ali S, Rasool M, Chaoudhry H, et al. Molecular mechanisms and mode of tamoxifen resistance in breast cancer. Bioinformation. 2016;12(3):135. doi:10.6026/bioinformation

7. Capasso I, Esposito E, Pentimalli F, et al. Metabolic syndrome affects breast cancer risk in postmenopausal women: national Cancer Institute of Naples experience. Cancer Biol Ther. 2011;10:1240-1243.

8. Gérard C, Brown KA. Obesity and breast cancer - role of estrogens and the molecular underpinnings of aromatase regulation in breast adipose tissue. Mol Cell Endocrinol. 2018;466:15-30. doi:10.1016/j. mce.2017.09.014

9. Ferraroni M, Gerber M, Decarli A, et al. HDL-cholesterol and breast cancer: a joint study in northern Italy and southern France. Int J Epidemiol. 1993;22:772-780. doi:10.1093/ije/22.5.772

10. Kitahara CM, Berrington de González A, Freedman ND, et al. Total cholesterol and cancer risk in a large prospective study in Korea. J Clin Oncol. 2011;29:1592-1598. doi:10.1200/JCO.2010.31.5200

11. Cote-Daigneault J, Mehandru S, Ungaro R, Atreja A, Colombel JF. Potential immunomodulatory effects of statins in inflammatory bowel disease. Inflamm Bowel Dis. 2016;22:724-732. doi:10.1097/MIB.000 0000000000640 
12. Kavalipati N, Shah J, Ramakrishan A, Vasnawala H. Pleiotropic effects of statins. Ind J Endocrinol Metabol. 2015;19:554-562. doi:10.4103/2230-8210.163106

13. Van Wyhe RD, Rahal OM, Woodward WA. Effect of statins on breast cancer recurrence and mortality: a review. Breast Cancer Targets Ther. 2017;9:559-565.

14. Lacerda L, Reddy JP, Liu D, et al. Simvastatin radiosensitizes differentiated and stem-like breast cancer cell lines and is associated with improved local control in inflammatory breast cancer patients treated with postmastectomy radiation. Stem Cells Transl Med. 2014; 3:849-856. doi:10.5966/sctm.2013-0204

15. Jin Y, Xu K, Chen Q, et al. Simvastatin inhibits the development of radioresistant esophageal cancer cells by increasing the radio-sensitivity and reversing EMT process via the PTEN-PI3K/ AKT pathway. Exp Cell Res. 2018;362(2):362-369. doi:10.1016/j. yexcr.2017.11.037

16. Li J, Liu J, Liang Z, et al. Simvastatin and Atorvastatin inhibit DNA replication licensing factor MCM7 and effectively suppress RB-deficient tumors growth. Cell Death Dis. 2017;8(3):e2673. doi:10. 1038/cddis. 2017.46

17. Undela K, Srikanth V, Bansal D. Statin use and risk of breast cancer: a meta-analysis of observational studies. Breast Cancer Res Treat. 2012;135:261-269. doi:10.1007/s10549-012-2154-X

18. Cronin-Fenton D, Lash TL, Ahern TP, et al. Concurrent new drug prescriptions and prognosis of early breast cancer: studies using the Danish Breast Cancer Group clinical database. Acta Oncol (Madr). 2018;57(1):120-128. doi:10.1080/0284186X.2017.1407040

19. Nielsen SF, Nordestgaard BG, Bojesen SE. Statin use and reduced cancer-related mortality. $N$ Engl J Med. 2012;367:1792-1802. doi:10.1056/NEJMoa1201735

20. Skehan P, Storeng R, Scudiero D, et al. New colorimetric cytotoxicity assay for anticancer drug screening. $J$ Natl Cancer Inst. 1990;82:1107-1112. doi:10.1093/jnci/82.13.1107

21. Chou TC. Theoretical basis, experimental design, and computerized simulation of synergism and antagonism in drug combination studies. Pharmacol Rev. 2006;58:621-681. doi:10.1124/pr.58.3.10

22. Buege AJ, Aust SD. Microsomal lipid peroxidation. Methods Enzymol. 1978;52:302-310.

23. Ellman GL. Tissue sulfhydryl groups. Arch BiochemBiophys. 1959;82:70-77. doi:10.1016/0003-9861(59)90090-6

24. Miranda KM, Espey MG, Wink DA. A rapid, simple spectrophotometric method for simultaneous detection of nitrate and nitrite. Nitric Oxide. 2001;5:62-71. doi:10.1006/niox.2000.0319

25. Bradford MM. A rapid and sensitive method for the quantitation of microgram quantities of protein utilizing the principle of protein-dye binding. Anal Biochem. 1976;72:248-254. doi:10.1016/0003-2697 (76)90527-3

26. Snoek-van Beurden PA, Von den Hoff JW. Zymographic techniques for analysis of matrix metalloproteinases and their inhibitors. Biotechniques. 2005;38:73-83. doi:10.2144/05381RV01

27. Gjerde N, Kisanga ER, Hauglid M, Holm PI, Mellgren G, Lien EA. Identification and quantification of tamoxifen and four metabolites in serum by liquid chromatography-tandem mass spectrometry. J Chromatogr A. 2005;1082:6-14. doi:10.1016/j.chroma.2005.01. 004

28. Motawia TK, Abdelazima SA, Darwisha HA, Elbaza EM, Shouman SA. Could caffeic acid phenethylester expand the antitumor effect of tamoxifen in breast carcinoma? Nutr Cancer. 2016;68:435-445. doi:10.1080/ 01635581.2016.1153669

29. Kochuparambil ST, Al-Husein B, Goc A, Soliman S, Somanath PR. Anticancer efficacy of simvastatin on prostate cancer cells and tumor xenografts is associated with inhibition of Akt and reduced prostate-specific antigen expression. PharmacolExpTher. 2011;336: 496-505.
30. Barroso-Sousa R, Silva DD, Alessi JV, Mano MS. Neoadjuvant endocrine therapy in breast cancer: current role and future perspectives. E Cancer Med Sci. 2016;10:609-623.

31. Bogush T, Dudko E, Bogush E, Polotsky B, Tjulandin S, Davydov M. Tamoxifen non-estrogen receptor mediated molecular targets. Oncol Rev. 2012;6(2):1-8. doi:10.4081/oncol.2012.e15

32. Hwang JJ, Kim HN, Kim J, et al. Zinc (II) ion mediates tamoxifen-induced autophagy and cell death in MCF-7 breast cancer cell line. Biometals. 2010;23:997-1013. doi:10.1007/s10534-010-9346-9

33. Bruning A, Friese K, Burges A, Mylonas I. Tamoxifen enhances the cytotoxic effect of nelfinavir in breast cancer cells. Breast Cancer Res. 2010;12:45-56. doi:10.1186/bcr2602

34. Yang S, Zhou Q, Yang X. Caspase -3 status is determinant of differential responses to genistein between MDA-MB-231 and MCF7 breast cancer cells. Biochim Biophys Acta. 2007;1773:903-911. doi:10.1016/j.bbamcr.2007.03.021

35. Tait SW, Ichim G, Green DR. Die another way - non-apoptotic mechanisms of cell death. J Cell Sci. 2014;127:2135-2144. doi:10. $1242 /$ jcs.093575

36. Mandal M, Kumar R. BcI-2 expression regulates sodium butyrate-induced apoptosis in human MCF-7 breast cancer cells1. A A. 1996;100:10.

37. Hanahan D, Weinberg RA. Hallmarks of cancer: the next generation. Cell. 2011;144:646-674. doi:10.1016/j.cell.2011.02.013

38. Rivenzon-Segal D, Boldin-Adamsky S, Seger D, Seger R, Degani H. Glycolysis and glucose transporter 1 as markers of response to hormonal therapy in breast cancer. Int $J$ Cancer. 2003;107 (2):177-182. doi:10.1002/(ISSN)1097-0215

39. Hesselbarth N, Pettinelli C, Gericke M, et al. Tamoxifen affects glucose and lipid metabolism parameters, causes browning of subcutaneous adipose tissue and transient body composition changes in C57BL/6NTac mice. Biochem Biophys Res Commun. 2015;464:724-729. doi:10.1016/j.bbrc.2015.07.015

40. Carmeliet P. Angiogenesis in life, disease and medicine. Nature. 2005;438:932-936. doi:10.1038/nature04478

41. Johnson KE, Forward JA, Tippy MD, et al. Tamoxifen directly inhibits platelet angiogenicpotential and platelet-mediated metastasis. Arterioscler Thromb Vasc Biol. 2017;37:664-674. doi:10. 1161/ATVBAHA.116.308791

42. Garvin S, Nilsson UW, Huss FR, Kratz G, Dabrosin C. Estradiol increases VEGF in human breast studied by whole tissue culture. Cell Tissue Res. 2006;325:245-251. doi:10.1007/s00441-006-0159-7

43. Nilsson UW, Garvin S, Dabrosin C. MMP-2 and MMP-9 activity is regulated by estradiol and tamoxifen in cultured human breast cancer cells. Breast Cancer Res Treat. 2007;102:253-261. doi:10.1007/s105 49-006-9335-4

44. Park MH, Hong JT. Roles of NF- $\kappa \mathrm{B}$ in cancer and inflammatory diseases and their therapeutic approaches. Cells. 2016;5:1-15. doi:10. 3390/cells5020015

45. Gopalan A, Yu W, Sanders BG, Kline K. Simvastatin inhibition of mevalonate pathway induces apoptosis in human breast cancer cells via activation of JNK/CHOP/DR5 signaling pathway. Cancer Lett. 2013;329:9-16. doi:10.1016/j.canlet.2012.08.031

46. Keyomarsi K, Sandoval L, Band V, Pardee AB. Synchronization of tumor and normal cells from G1 to multiple cell cycles by lovastatin. Cancer Res. 1991;51:3602-3609.

47. Sanchez CA, Rodriguez E, Varela E, et al. Statin induced inhibition of MCF-7 breast cancer cell proliferation is related to cell cycle arrest and apoptotic and necrotic cell death mediated by an enhanced oxidative stress. Cancer Investig. 2008;26:698-707. doi:10.1080/ 07357900701874658

48. Ghosh-Choudhury N, Mandal CC, Ghosh-Choudhury N, Ghosh Choudhury G. Simvastatin induces depression of PTEN expression via NFkB to inhibit breast cancer cell growth. Cell Signal. 2010;22:749-758. doi:10.1016/j.cellsig.2009.12.010 
49. Spampanato C, De Maria S, Sarnataro M, et al. Simvastatin inhibits cancer cell growth by inducing apoptosis correlated to activation of Bax and down-regulation of BCL-2 gene expression. Int J Oncol. 2012;40:935-941. doi:10.3892/ijo.2011.1273

50. Taha DA, De Moor CH, Barrett DA, et al. The role of acid-base imbalance in statin-induced myotoxicity. Transl Res. 2016;174: 140-160. doi:10.1016/j.trs1.2016.03.015

51. Wang G, Cao R, Wang Y. Simvastatin induces cell cycle arrest and inhibits proliferation of bladder cancer cells via PPAR $\gamma$ signaling pathway. Sci Rep. 2016;6:35783. doi:10.1038/srep35783

52. Sohn HM, Hwang JY, Ryu JH, et al. Simvastatin protects ischemic spinal cord injury from cell death and cytotoxicity through decreasing oxidative stress: in vitro primary cultured rat spinal cord model under oxygen and glucose deprivation reoxygenation conditions. J OrthopSurg Res. 2017;12:36-44.

53. Kanugula AK, Kotamraju S. Statin-induced molecular mechanisms of breast cancer cell death: recent developments. Cancer Cell Microenviron. 2014;1:e390.

54. Brewer TM, Masuda H, Liu DD, et al. Statin use in primary inflammatory breast cancer: a cohort study. Br J Cancer. 2013;109: 318-324. doi:10.1038/bjc.2013.342

55. Nowis D, Malenda A, Furs K, et al. Statins impair glucose uptake in human cells. BMJ Open Diabetes Res Care. 2014;2:e00017. doi:10. 1136/bmjdrc-2014-000017

56. Malenda A, Skrobanska A, Issat T, et al. Statins impair glucose uptake in tumor cells. Neoplasia. 2012;14:311-323. doi:10.1593/ neo. 12444

57. Coimbra M, Banciu M, Fens MH, et al. Liposomal pravastatin inhibits tumor growth by targeting cancer-related inflammation. J Control Release. 2010;148:303-310. doi:10.1016/j.jconrel.2010.09.011

58. Shen Y, Du Y, Zhang Y, Pan Y. Synergistic effects of combined treatment with simvastatin and exemestane on MCF-7 human breast cancer cells. Mol Med Rep. 2015;12(1):456-462. doi:10.3892/mmr.2015.3406

59. Buranrat B, Suwannaloet W, Naowaboot J. Simvastatin potentiates doxorubicin activity against MCF-7 breast cancer cells. Oncol Lett. 2017;14:6243-6250. doi:10.3892/ol.2017.6783

60. Abdoul-Azize S, Buquet C, Li H, Picquenot JM, Vannier JP. Integration of $\mathrm{Ca}^{2+}$ signaling regulates the breast tumor cell response to simvastatin and doxorubicin. Oncogene. 2018;37(36):4979-4982. doi:10.1038/s41388-018-0329-6

61. Liang Z, Li W, Liu J, et al. Simvastatin suppresses the DNA replication licensing factor MCM7 and inhibits the growth of tamoxifen-resistant breast cancer cells. Sci Rep. 2017;7:41776-41786. doi:10.1038/srep41776
62. Shaitelman SF, Stauder MC, Allen P, et al. Impact of statin use on outcomes in triple negative breast cancer. J Cancer. 2017;8:2026-2032. doi:10.7150/jca.18743

63. Göbel A, Breining D, Rauner M, Hofbauer LC, Rachner TD. Induction of 3-hydroxy-3-methylglutaryl-CoA reductase mediates statin resistance in breast cancer cells. Cell Death Dis. 2019;10 (2):91. doi:10.1038/s41419-019-1322-x

64. Armengol S, Arretxe E, Enzunza L, et al. SREBP-2-driven transcriptional activation of human SND1 oncogene. Oncotarget. 2017;8 (64):108181. doi:10.18632/oncotarget.v8i64

65. Arretxe E, Armengol S, Mula S, Chico Y, Ochoa B, Martinez MJ. Profiling of promoter occupancy by the SND1 transcriptional coactivator identifies downstream glycerolipid metabolic genes involved in TNF alpha response in human hepatoma cells. Nucleic Acids Res. 2015;43:10673-10688. doi:10.1093/nar/gkv858

66. Ma H, Yao Y, Wang C, et al. Transcription factor activity of estrogen receptor $\alpha$ activation upon nonylphenol or bisphenol A treatment enhances the in vitro proliferation, invasion, and migration of neuroblastoma cells. Onco Targets Ther. 2016;9:3451.

67. Li X, Song QS, Wang JY, et al. Simvastatin induces estrogen receptor-alpha expression in bone, restores bone loss, and decreases ER $\alpha$ expression and uterine wet weight in ovariectomized rats. $J$ Bone Miner Metab. 2011;29(4):396-403. doi:10.1007/s00774-010-0231-y

68. Du Meng ML, Han Y, Zhao D, Zhang X, Yang Y, Liu R. MicroRNA645 targets urokinase plasminogen activator and decreases the invasive growth of MDA-MB-231 triple-negative breast cancer cells. Onco Targets Ther. 2018;11:7733. doi:10.2147/OTT.S187221

69. Klein G, Vellenga E, Fraaije MW, Kamps WA, Bont ES. The possible role of matrix metalloproteinase (MMP)-2 and MMP-9 in cancer, e.g. acute leukemia. Crit Rev Oncol Hematol. 2004;50:87-100. doi:10.1016/j.critrevonc.2003.09.001

70. Thunyakitpisal PD, Chaisuparat R. Simvastatin, an HMG-CoA reductase inhibitor, reduced the expression of matrix metalloproteinase- 9 (Gelatinase B) in osteoblastic cells and HT1080 fibrosarcoma cells. J Pharmacol Sci. 2004;94:403-409. doi:10.1254/jphs.94.403

71. Kang S, Kim ES, Moon A. Simvastatin and lovastatin inhibit breast cell invasion induced by H-Ras. Oncol Rep. 2009;21:1317-1322. doi: 10.3892 /or 00000357

72. Chen YJ, Chang LS. Simvastatin induces NF kB/p65 down-regulation and JNK1/c-Jun/ATF- 2 activation leading to matrix metalloproteinase-9 (MMP-9) but not MMP-2 down-regulation in human leukemia cells. Biochem Pharmacol. 2014;92:530-543. doi:10.1016/j.bcp.2014.09.026

\section{Publish your work in this journal}

Cancer Management and Research is an international, peer-reviewed open access journal focusing on cancer research and the optimal use of preventative and integrated treatment interventions to achieve improved outcomes, enhanced survival and quality of life for the cancer patient.
The manuscript management system is completely online and includes a very quick and fair peer-review system, which is all easy to use. Visit http://www.dovepress.com/testimonials.php to read real quotes from published authors. 